\title{
A Spatial Analysis of Domestic Architecture in Khartoum: Transitional Praxis of Colonial to Post-Colonial Private Houses
}

\author{
Gadsiah Ibrahim \\ Lecturer \\ Tallal A. Saeed \\ Assistant Professor \\ Department of Architectural Design, Faculty of Architecture, University of Khartoum, Sudan \\ gadsiah.ibrahim@outlook.com \\ saeetal@iit.edu
}

(Received 17/2/2019; accepted for publication 23/6/2019.)

\begin{abstract}
The intricate changes on domestic social patterns around the time of independence (1956) in Khartoum represent the focus of this paper, which aims at providing space syntax-based viewpoint of the transition. The built representation of the political change, which had towed economic, cultural and social transformation, has not been well investigated in Khartoum. The domestic architecture is envisaged here to reflect the change from a liberal and secular British lifestyle to a conservative and religious one, characterized by the natives. The study hence, explores twenty representative samples from the two periods in order to reveal the hidden nature of these patterns, employing the Space Syntax method of analysis; particularly the convex mapping. This analysis seeks to both decipher space transition and identify patterns. In order to interpret the social meaning of these configurations and to factor out the historical context of the transition, several interviews were conducted. The analytical comparisons revealed that these socio-cultural changes had subtle effects on the transformations experienced in the use and organization of spaces. The change shows that the emerging dominance of privacy in relation with exterior has started to diminish, and some interior spaces were redefined. These privacy-centered patterns, in many post-colonial cases as well, have pushed the core of integration deeper in the access 'graph'.
\end{abstract}

Keywords: Khartoum, Transition, Colonial, Spatial organization.

\section{Introduction}

Among the current wave of social transformation studies of the post-colonial communities, the case of Khartoum stands distinct. Khartoum's colonial rule (1898-1956) had restructured the country's social, economic and political bases, and thus had accelerated the pace of urban growth in the Sudan in drastic ways (Ibrahim et.al, 2014). The impact of this rule was clearly felt by all of the modernization urban agencies (education, transportation, and the establishment of several new urban centers). Khartoum, even if it was not a colony in a territorial sense, was considered one of the most important British colonies (Sharkey, 2007). Hence, the study of its social transformation around the time of independence requires re-evaluation, considering the emerging benefits of space syntax analysis. Of all the political changes witnessed in the history of the new city (founded formally in 1820 's), which have been naturally followed by social changes and effects on the built-form, the 'Sudanization' after 1956 occupies an important place $^{1}$. The manifestation of these social changes could be particularly reflected and traced in the domestic spatial organization. Despite the gradual nature of the transformation at this level (figure 1), this paper hypothesizes that the contradictory dynamics, represented in several layers of duality and multiplicity, can

1. Especially when considering the fact that the Egyptians and/or Turkish domestic had left almost nothing due to the great devastation by the Mahadists (1885-98) (Ashley, 2013) 


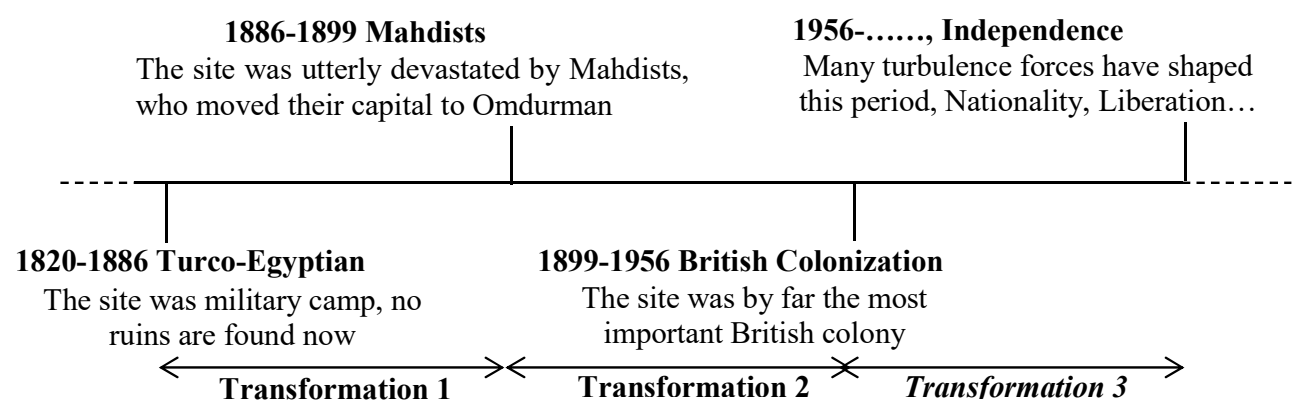

Figure 1. transfomation milestones of Khartoum

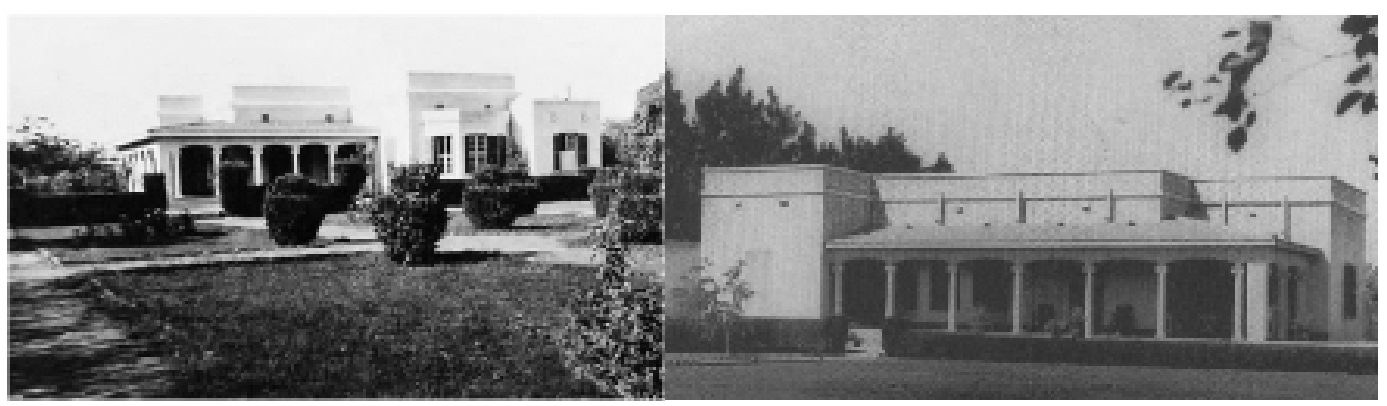

Figure 2. British houses. (Source: Daly, 2005)

be explored via the variation of the ordering of space, for instance, as a conspicuous dimension of culture, which can be best measured by its transition.

One of the significant transformations occurred to those British-inhabited houses (figure 2), which had been re-occupied later by the Sudanese elites after independence. This new people's behaviour, of conservative culture, overlapped with high relaxation of code rule of the precedent colonizers. The early batches of educated Sudanese Elites came from traditional houses, in which spaces were divided into areas for men, located right behind the gateway, and a more withdrawn area for women and domestic functions (Schulz, 1980). Those houses, characterised with this high level of segregation between male and female domains, are now exposed and influenced by western ways of eating, dressing and talking. The new occupants, however, were not completely detached from their traditional and cultural backgrounds in which they have been brought up (Elhassan, 2016). As such they seem to be living in two interrelated worlds.

Those individuals, who owned those houses, considered themselves socially superior (Nguluma, 2003), had preserved the established social stratification implemented through colonizer's zoning ordinance.

The representation of this transformation, as a domestic spatial organization (figure 3), was affected by a couple of contradicting realities. First, the persistence of cultural tension of colonial structures, between the British and native, has been replaced by native and the entire western culture. British with their own culture aimed at obliterating local identity to an inferior position superseded by their control of the economy, politics and social relationships (Elhassan, 2016). For the political elite of the new post-colonial nation, providing a totally new national identity draws on its own vernacular cultures, constructing new identities, by rejecting the old, and creating new indigenous modernity (King, 2009).

A second level of complexity manifested itself in the hybridity of the colonial houses ${ }^{2}$, that had resulted from the slow interaction of the adapted domestic architecture ${ }^{3}$ on the one hand, and the existing multi-cultural communities on the other. Special concerns were paid by recruiting

2. Domestic architecture-nevertheless it was initiatively meant for the British settlement who they did not accompany families.

3It is found that the interaction between imperial and the indigenous practices lead to the cross-breeding cultures results in hybridity, that is not originated in the colonizer mother country as Christophe Charley stated in «Maisons de maître et habitations colonialesdans les anciensterritoiresfrancais de 1>Ameriquetropicale». 


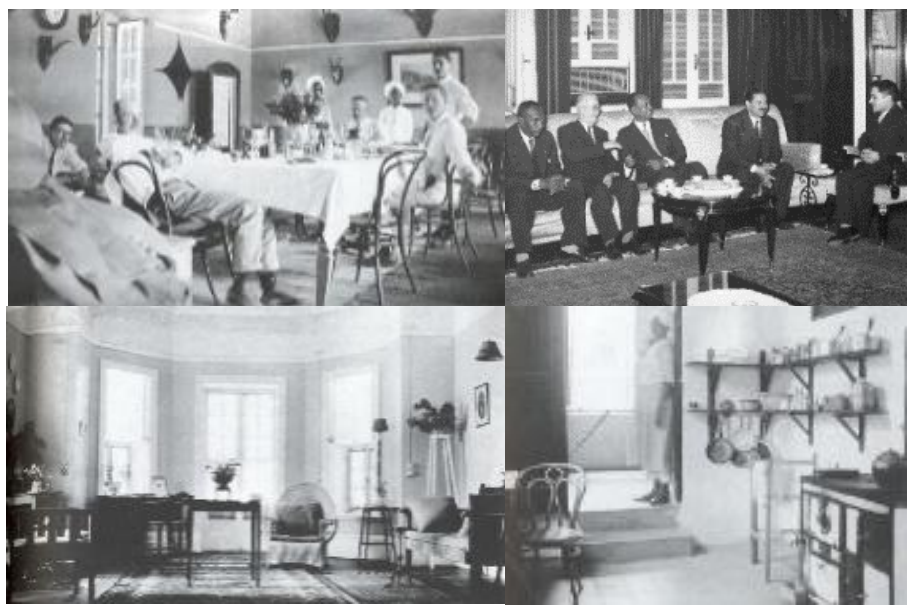

Figure 3. British houses. (Source: Daly, 2005)

Khedive (the title of the viceroy of Egypt under Turkish rule) and Royal Architects to incorporate the new physical environment (climate, material and technology) into an architectural style (Osman et al., 2014). This incorporation was experimented with in well rooted traditions of Arabic-African character; for instance, while enclosures of houses were derived from the social structure of Arab-Muslims, tectonics depended predominantly on local traditional African materials (Bani, 2014).

Third, the period leading to independence concurred with major global revolutions represented in the start of decline of Modernism (as an architectural school), the rise of regional powers/identities and modern technological advances. These realities congregate to demonstrate a complex identity problematic that refuses simple correlational dependence.

The investigation of the transformations within this given cultural context adopts hereby the space syntax theory as a contemporary tool that gives a new reading for this recent history. A comparative analysis of 20 samples focusing on the depth \& pattern, integration-segregation, and on pattern and difference, was conducted to evaluate the degree of change (rapidly, slowly), whether it has followed an evolutional process or has faced any kind of break-up.

\subsection{The transformation of spatial organization of the social patterns}

The syntactical studies of the upper northeast houses in Thailand investigate how vernacular houses (figure 4) in term of spatial and functional organization, have developed their patterns to support the emerging lifestyle. The analysis indicates a continuous transition of space-use pattern in accordance with the change of life-

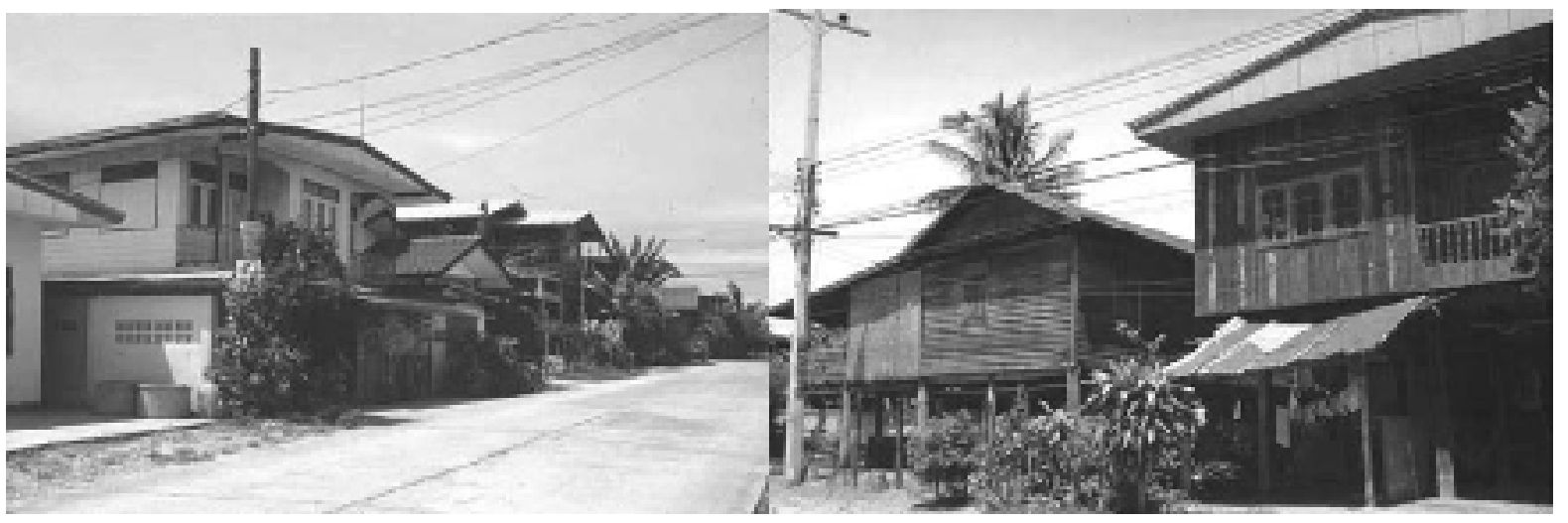

Figure 4. Modern vs. vernacular houses in Thailand. (Source: Thungsakul, 2002) 
style and the shift from vernacular familyism to individualism. The patterns from various house types not only illustrate different domestic experience but also identify the impact of physical transformation by the process of urbanization (Thungsakul, 2002).

The change of spatial organization may become an indication of society evolution. Neeta and Dongre (2016) adopt the Space Syntax to explore the social relevance of the spatial organization of the traditional houses of Ahmadabad; their study indicates that the traditional layout has changed its spatial hierarchy dictated by the social conditions that requires high integration with community.

Erman (2017) carried out a comparative analysis of the change in spatial organization in Turkey, from the religious Ottoman Empire to the contemporary secular state. Using Space Syntax techniques has shown that the cultural, social and economic changes influence the transformations in the domestic spatial configuration. In addition, the developments in technology lead to important changes, like re-definition of service spaces, and changed the multifunctional character of space (figure 5). Traditional houses hence, can be classified as introverted (facing the inner spaces) while, the houses of the Early Republican Era are mostly extroverted (facing the street/front gardens). This can mainly be referred to the transformations in the family structure, lifestyle, and to the change from communality to individuality parallel to shift in society from traditional to modern.

The importance of using space syntax, as a suitable tool for defining similarities and differences between different environments, has led to highlight the ingrained socio-cultural elements of spatial organizations in the houses and understand the hidden pattern of spaces. Space syntax is considered as new paradigm to read the history of the different transformed situations (vernacular-modern) change, or (conservativeliberal) shift, and detect the evolution of spaces.

\subsection{The influence of the coloni er's legacy on the local context}

The influence of colonial (British) rule on native (Indian) culture has resulted in the development of "hybrid" architectural styles, as an important phase in the evolution of domestic architecture in India. To explore whether such hybrid style is merely seen in the external "form" of the buildings, or is also reflected in the spatial organizations of colonials, Bandyopadhyay and Merchant (2006) use Space Syntax analysis through physical descriptions of form to analyse functions carried out in various spaces. This resulted in the development of bungalows and other forms of houses for the Europeans in India since the British, with their eclectic mixture, took into account the special demands of the climate of the region (Metcalfe, 1984). The Indians were also influenced by the colonizers as the hybrid style represented a beginning of evolution.

From a space synthesis point of view, and that of the quality of colonial influence houses on the traditional ones (Table 1), qualitative research based, on plans, has revealed that Benin colonial domestic architecture could be considered a "tabula rasa" for transition (Ekhaese, 2014). Benin has undergone a series of transformations that reflect not only the simple change in spaces arrangement, but also the hidden interactions between the spaces and the activities defining new spaces. The French, according to the study, have added and integrated their architectural elements, modified them to suit the climate into traditional architecture. It aimed at presenting the integration by indicating the significant role of culture, customary practices, and local constructional methods on the creation and configuration of the colonial architecture (Vongvilay et al., 2015), and this is considered the beginning of the development of the Lao domestic architecture.

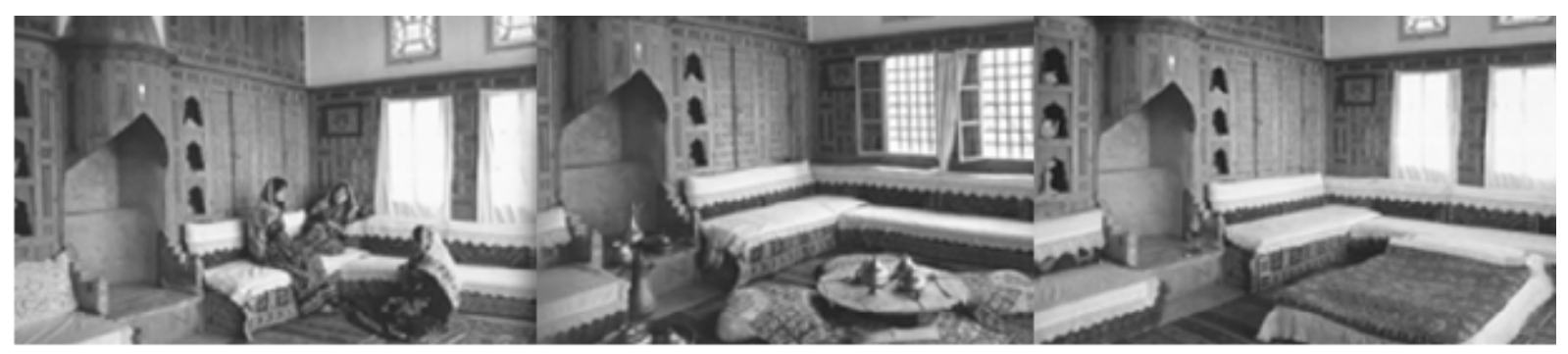

Figure 5. The multifunctional character of rooms in traditional houses. (Source: Erman, 2017) 
Table 1.Comparisons between houses. (Source: Ekhaese, 2014)

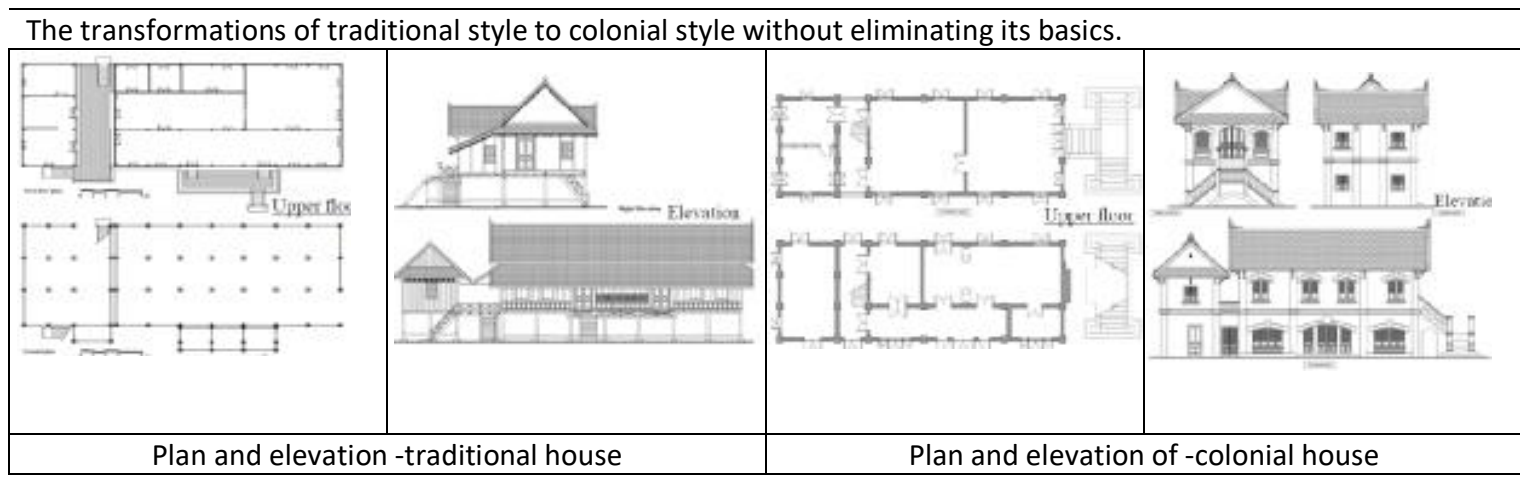

Unlike the interaction with existing traditional legacies of Lao, Benin, and India, in which the transition leads to hybrid production, this study is limited to the transition that parallels the political shift from colonial to post-colonial period on a site that had been constructed from the scratch.

\section{METHOD}

To test the consistencies of spaces arrangements, and the way uses are assigned to different interior spaces, overall system analysis (J-graph) and individual space analysis (applies syntactic values of IV and MD) are calculated, then, the syntactic values are interpreted to reveal the transition of internal spaces.

\subsection{Data collection}

The required information about the activities, attitudes of occupants, and physical features, are collected from multiple data sources to maximize the accuracy of the results. Primary data is obtained from selected case studies in the form of measured drawings, photographs and interviews. Secondary data is collected from available literature. A content analysis is performed to the latter and comparative analysis to the former.

\subsection{Samples selection}

It is necessary to define the area that had experienced major interactions with colonizers and has enough existing cases to be examined. These selected zones of figure 6 vary between those designed and built by professionals, and those produced by builders or local contractors.
The collected twenty samples (20 houses) were based on the following criteria:

- The house largely maintained its original construction.

- The original/early inhabitants are likely to be contactable regarding their experiential perceptions.

- Documentation is available on the house, or permission to study the interior is attainable.

The cases are situated in: Khartoum 1, Khartoum-East, Al-amarat, Burri, Hai el-Matar (Appendix A). In this contexts, the intensity of interaction between the natives (Anglicized Sudanese) and the British, with adoption of European culture to intersperse with the local culture, was more prominent, and corresponded with the remaining houses that are still occupied by their original owners (figure 7).

\subsection{Methods of data analysis}

To understand how spatial configuration is expressed, the spatial categories of the two periods are compared to each other, to reveal different dimensions of the changes of spaces. Space Syntax analysis is employed, to identify how spatial organization change according to specific parameters. The data is then arranged to compare the commonalties and differences of the pattern of spatial organization in the transition.

The way space is structured by inhabitants can provide understanding of experience in account of social system and organizational rules of the built spaces (Hillier \& Hanson, 1984). These rules must themselves be identified. To trace the transmission (figure 8), generally the core' must be defined, and then analyzing continuity and 


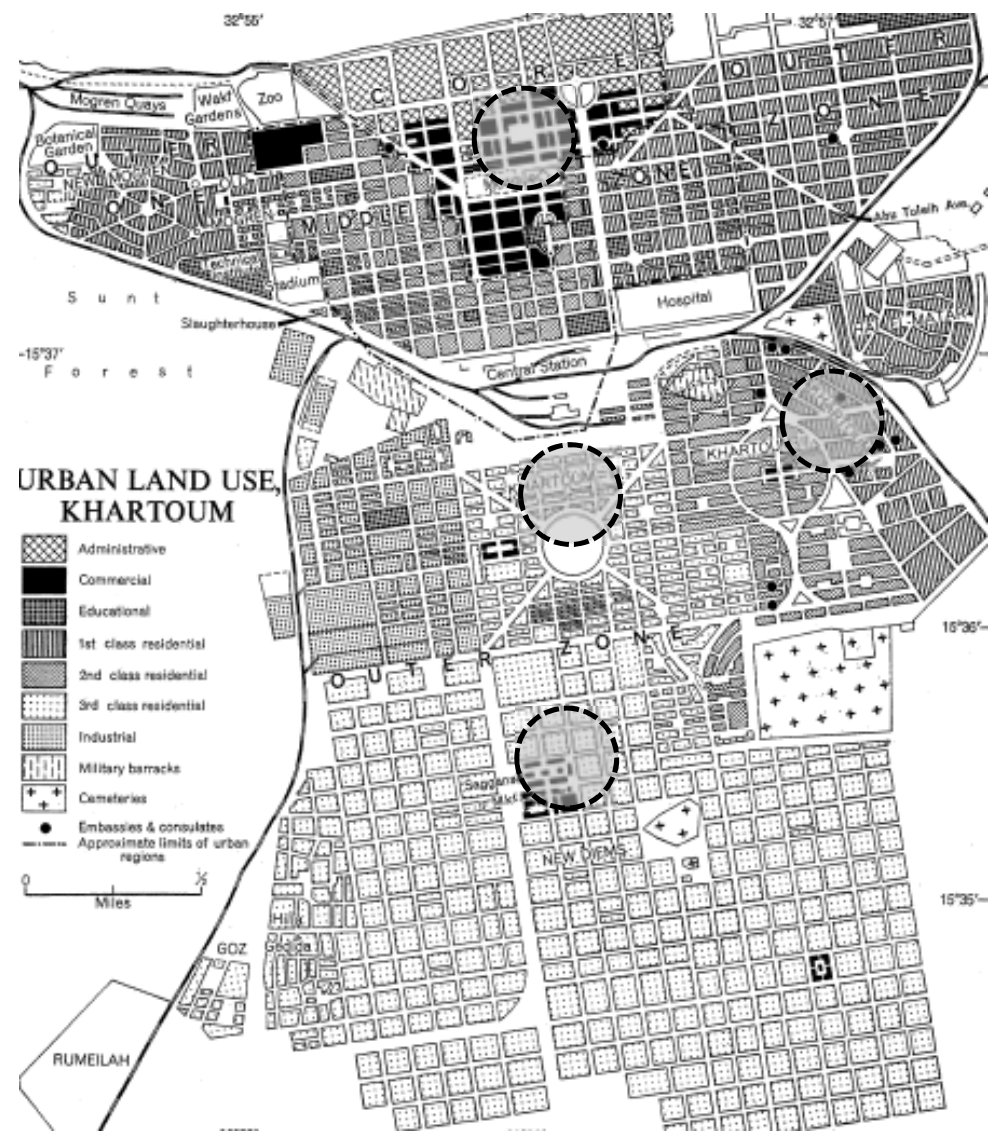

Figure 6. Locations of cases in the old Khartoum map. (Source: Hamadan 1969)

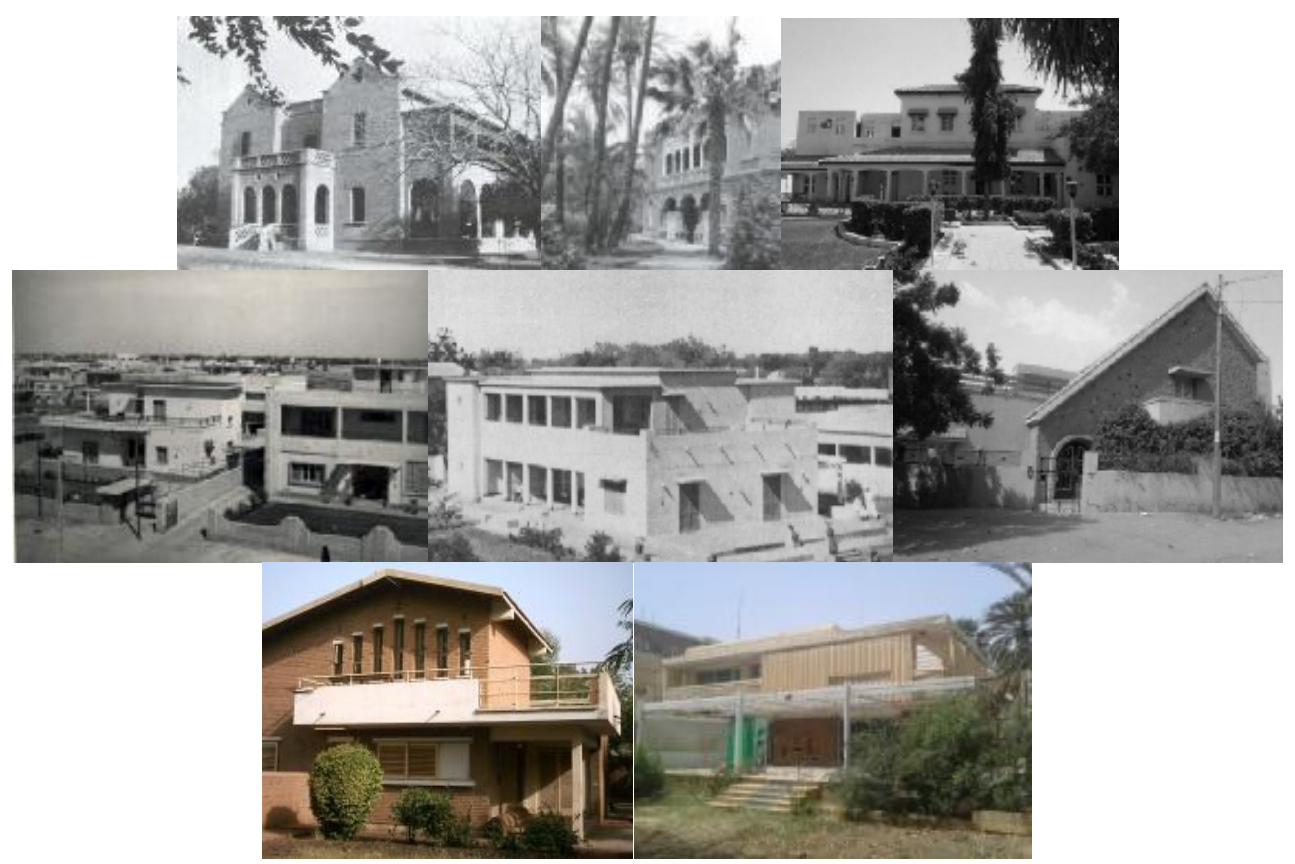

Figure 7. From upper left, colonials $(\mathrm{C} 01, \mathrm{C} 03)$, periods in between $(\mathrm{C07}, \mathrm{C08})$, and post-colonials houses in $\mathrm{Khartoum}(\mathrm{P02}$, P06). (Source: Daly 2005, Hamadan 1969, Author) 


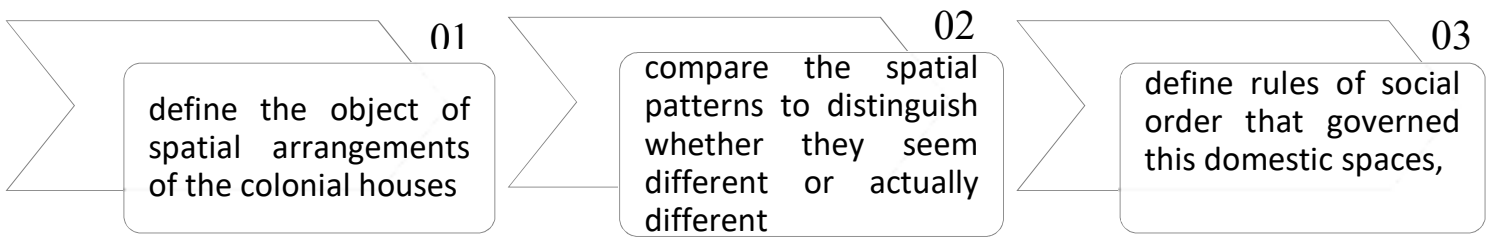

Figure 8. Analysis Process

change integrate the analysis of built form with social, cultural, economic and historical aspects.

As Convex map is often used to discuss the arrangement of programmatic (Bafna, 2003), it is employed here to produce:

- A Justified Graph Analysis (J-Graph) that reveal the topology of a spatial organization.

- Then it is subjected to mathematical analysis to produce: Mean Depth (MD), Real Relative Asymmetry (RRA), Integration Values (IV), and Difference Factor (DF).

To tackle the difference between how space is occupied and used during normal social time, and how the house is transformed to meet special needs, a common ground of assigning all the spaces to broader platform for comparison was established to be unified across all samples. The categorization of (table 2) was divided into four families of functional clusters as below:

These clusters are merged with another layers of hatching to each use (social, private, and servants), figure 9 shows the construction of zones for living and service zones to test their relationship.

Whereas the labeling of spaces has been carried by its function (sitting room, living room), or use/activity (sleeping area, eating area), or by its furniture, no problems are raised for syntax for this activities which take place in one space. They all acquire the configurational properties of that space (Hillier \& Hanson, 1982). Similarly, if several numbers of spaces are assigned to a single activity, the values are averaged for the set of all spaces to draw an overall result.

\section{RESULTS}

The syntactical data are generated from: the total depth, mean depth, relative asymmetry, real relative asymmetry, and the integration values, to test the nature of transition among spaces.

Table 2. Spaces categorization clusters

\begin{tabular}{ll}
\hline Living spaces & $\begin{array}{l}\text { For inhabitants and visitors spaces: Entrance Halls } E H \text {, Bedrooms } B R, \text { Living } \\
\text { room } L V \text {, Sitting Room } S I .\end{array}$ \\
\hline Exterior spaces & Garden $G R$, Yard $Y D$, Terraces $T R$, Balcony $B C$, external Stair $S T^{*}$ "if found". \\
\hline Circulation spaces & Lobbies $L B$, passages $P S$, and stair $S T$ \\
\hline Service-related spaces & Kitchens $K T$, Bathrooms $B T$, Stores $S R$. \\
\hline
\end{tabular}

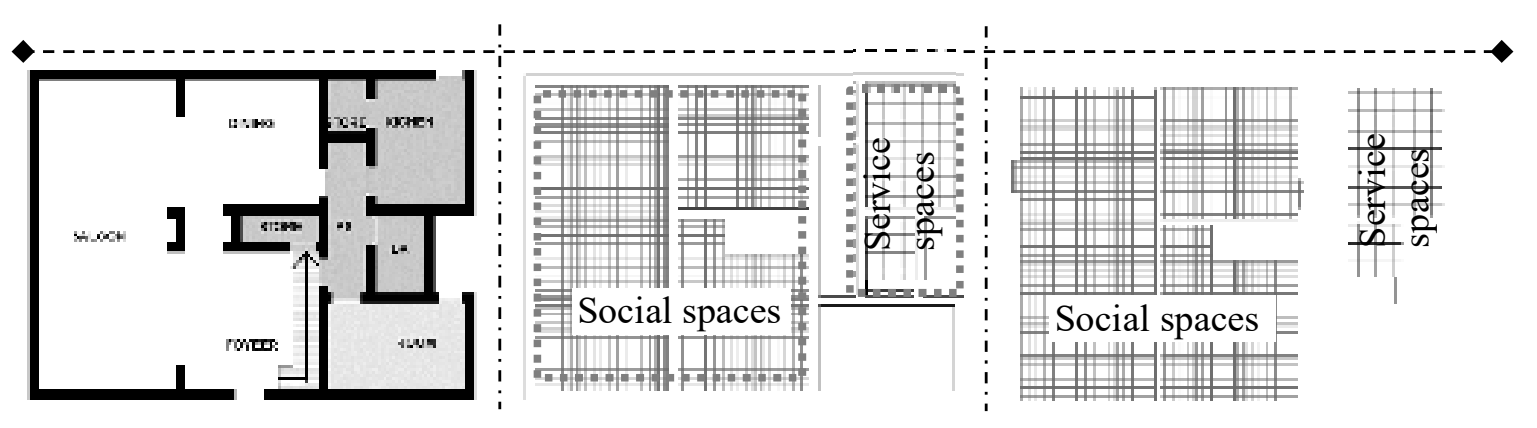

Figure 9. Hatching applied to living and Service zones (P07) 


\subsection{Pattern and difference (Configurational analysis $^{4}$ )}

The justified graphs of samples are different from each other, but some discernible coherence in the rankings of these samples could be observed in figure 12 .

3.1.1 Ring arrangement of figure 10 compensates the overwhelming preponderance of Shallow Bush forms (Diffusion of spatial control A) of colonials with deep tree/Ring structure, (superordinate control and Integration of social categories B, D) for post-colonials, linked to each other at one, two, or more levels. Sociologically speaking, deep tree offers no choice to navigate the building; however, spatially speaking, the shallow bush contains more spatial units. The double sequence with a lot of levels was the attribute of the late post-colonial that led to weaker function relationship.

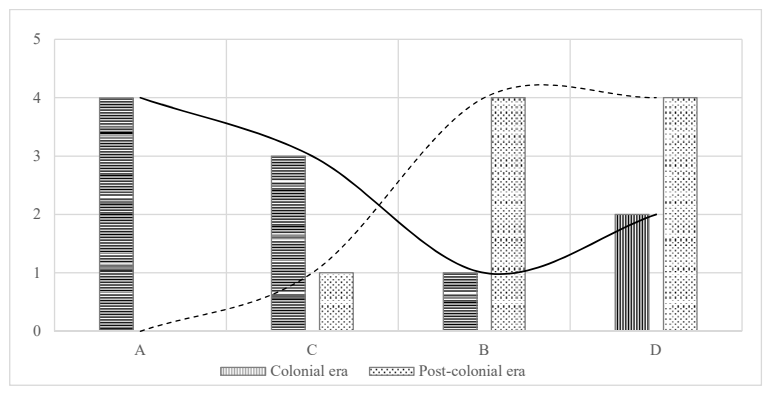

Figure 10. Ring type's distribution

Unsurprisingly the most of shallow bush (A) and shallow ring (C) systems have the highest mean Integration and the deep tree-like form, and is the most segregated configuration. Shallow bush and the deeper ring complex have the same mean or overall integration. The difference between them lies in how integration is distributed.

The houses are situated within a garden/yard with one entrance, which, in turn, is connected to the exterior, in some cases the exterior is directly connected to a kitchen, veranda/ mustaba or stairs. The access level above the garden is generally occupied by the visitors', circulation, and service spaces (only for colonial). The private spaces generally occur at the higher levels (one degree deeper for post-colonial). Houses are nearly similar in terms of areas, and there are no striking differences in the plot width which inevitably would not call for any constraints on arrangements program that may be driven by the site.

The predominance of combination of $55 \%$ (Garden + veranda) for colonial (figure 11) compensated by $63 \%$ of (Garden+ living), followed by (Yard + living), in correlation to the most rank order of integration (Appendix C). This value adds to that of dependence on the interior spaces with extension to outdoor in post-colonial.

3.1.2 No effect of size on integration was found. Both shallow bush and ring disappear in postcolonial unless those who retain the same characteristics. All the cases with more number of spaces tend to either organize in deep ring or in tree, particularly in late colonial, but it never affects its integration value. 3.1.3 Graphs based on some transitional spaces (while exterior or interior) provide connections to various spaces and segregate the spaces from one another, such as veranda/garden (exterior + function) in colonials, and foyer or passage (interior + circulation) in post-colonial. Most of spatial units have access from these spaces.

Around the total of $80 \%$ of rooms open directly to the living space or exterior (veranda), only $20 \%$ open into passages or lobbies for

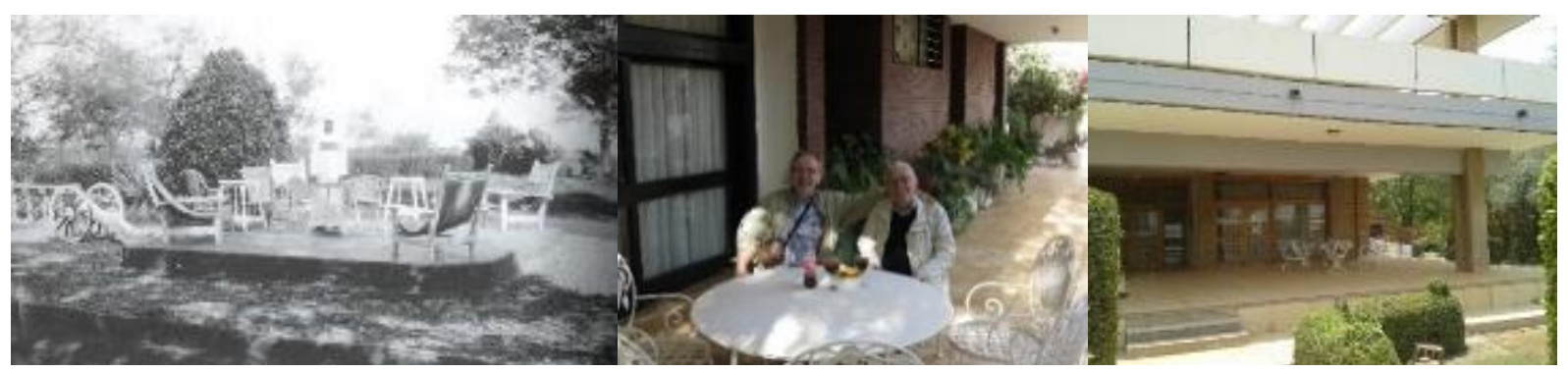

Figure 11. The use of verandah and the garden in colonial (C01-C04) vs. post-colonial (P07, P09). (Source: Daly 2005, Owners' album, Author)

4. All justified graphs have been taken from the carrier, and are integrated with exterior. 

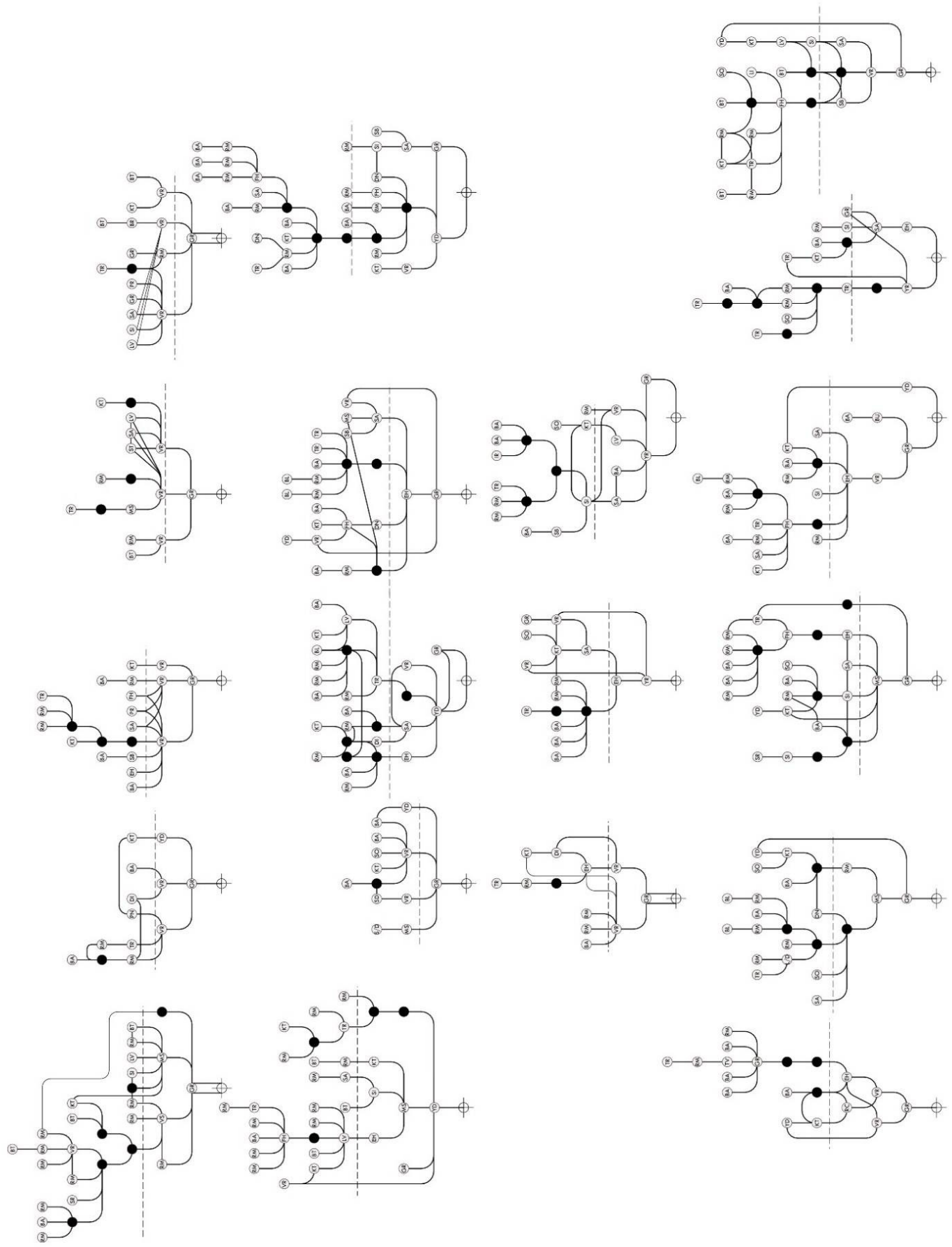

Figure 12. Spatial arrangement across time 
colonials, whereas in most post-colonials, rooms open to more private spaces, enfold around circulation space (figure 13). Rooms could be reached without going through another space compared to most colonials' rooms, which have

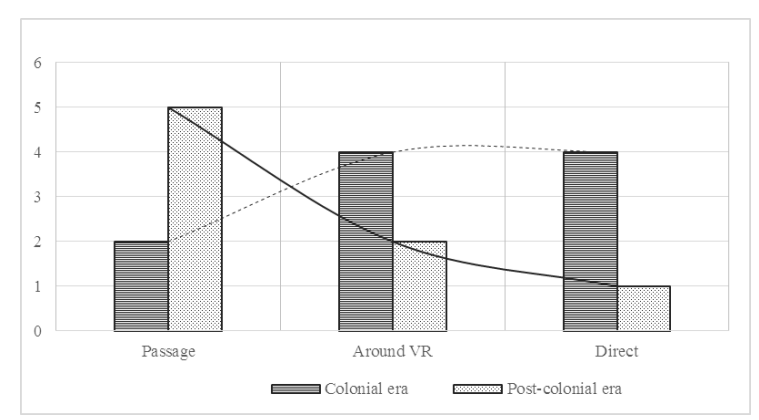

Figure 13. The connection of rooms to other spaces

given several connections breaking the privacy.

However, this spatially shifting to highly integrated passage turns the core of the house to an empty place. In the cases: C01, P09, P08, P06, the end of upper passage lies the back-stair, for the isolation of guest, inhabitant and servants.

All the bathrooms of colonial opened directly to living spaces, and for all post-colonials they open to the lobby or passage which indicates the level of privacy needed.

3.1.4 Dead ends (table 3) increase and occupy different levels in post-colonial. All baths are dead ends, rooms if not in dead end, are on the way to dead ends. $60 \%$ of colonial dead ends spaces are not found in last levels (Non- compatible with its position in system). It is, hence, in spatial segregation, but physically not on the deepest side of the house structure, nor at the back of the house. Post- colonials maintain this picture but in the reverse way.

The space link ratio shows that rings are found in almost all samples. The alternative connections between spaces are observed much less in colonials (having a small number of rings within their

Table 3. : Percentage of the dead end spaces

\begin{tabular}{ccc}
\hline Space & Colonials \% & Post-Colonials \% \\
\hline Kitchen & 60 & 35 \\
\hline Saloon & 20 & 10 \\
\hline Verandah & 0 & 40 \\
\hline Garden & 0 & 20 \\
\hline Bathrooms & 100 & 75 \\
\hline
\end{tabular}

Most dead ends occurrence spaces configurations) than in the post-colonial (having more rings offers a degree of flexibility pattern) due to the increase from 1.14 to 1.16 . This reflects simpler space organizations of colonials. Only case (C08) and (P04) have no rings because of their space link ratio being equal to 1 . Common rings connect guest domains of colonial spaces, and connect different spaces/social and back/ front house or veranda and attached social spaces in post-colonial.

When the connectivity is examined, it is found that decrease in depth level means increasing integration regardless of the connectivity of space for the colonial (Appendix B). Post-colonial shows consistent pattern in the relationship between spaces connectivity and links.

3.1.6 Another marked difference, is that the T-centred was $20 \%$ to $67 \%$, in contrary to $80 \%$ to $33 \%$ as function-centred as in figure 14 . This is supported with variation in the tran:func ratio from 0,10 to 0,16 , due to including pivotal space as circulation distributor, along with a central space that controls both interior and exterior relations (Appendix B). The colonials rarely show pivotal spaces, except in some late colonials as entrance hall. They enfold around double-center system with less sense of central space.

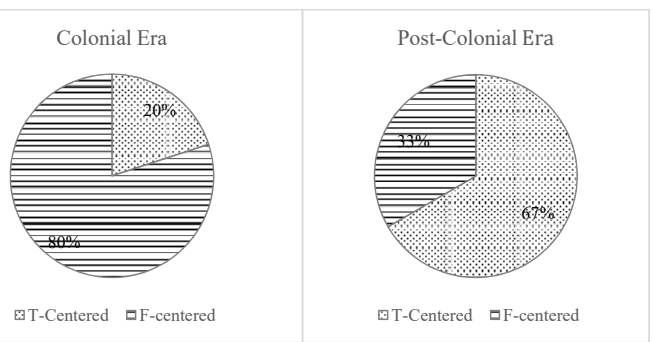

Figure 14. The distinction between transition-centred and function-centred

The most integrated function spaces were the sitting room and entrance hall. The rest of cases are dominated by exterior. The separation of the passage from the room later developed into the function of the corridor.

In general, (figure 15) shows that postcolonial has more transition spaces, less integration with exterior, deep structure systems and more homogenous spaces. The high difference factors in the samples indicate that there is no major difference between the integration 
values of the spaces that are allocated for different functions. Although the number of spaces decreased in post-colonials, the cases show homogeneity among spaces with the increase in DF from 0.76 to 0.80 .

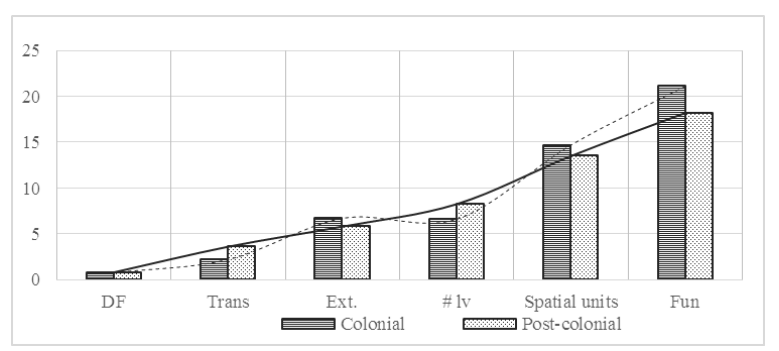

Figure 15. Different syntactical comparisons

\subsection{Depth and integration}

Handson (1998) stated that the depth can carry culture, so in the range of 5-10 level of depth in the colonial, compared to 6-9 in the post-colonial, the average of 6.9 , compared to 7.89 means that the post-colonial has more levels and less integration value. It is after independence that the privacy demand increased, the Sudanese started to respond to socio-cultural aspects.

The MD value, which is 3.45 for colonial (figure 16), indicates a symmetric order that connects to the carrier directly. In contrast to the 3.57 in post-colonial appear in asymmetric away from the carrier. Low mean value of RRA (1.21) of post-colonial supported tendency of the system to be more segregated (less accessible and more controlled). In both cases the maximum integrated case is nearly doubled the less integrated case value. The two periods consistently show similarities of accumulation in the cases around same clusters values.

When the relationship with exterior is examined in figure 17 and (Appendix C), the more integrated without exterior (increase in RRA due independency (absence) on exterior) are considered to be more closed and interior-oriented. The increase of the RRA in all colonial, from 1.11 to 1.18 in post-colonial, indicates the extensive use of exterior (fall into integrated side), especially garden and yard (interview and literature supported this fact).

3.2.1 The houses of the colonials tend to have simpler layouts, no circulation hall, and usually bedrooms are linked directly to living and/or dining areas. The houses of the late colonial tend to be more differentiated in terms of private versus public regions, and have more elaborate layouts.

The total number of spaces and the family of cluster function ${ }^{5}$ (F.C) are more elaborate in colonial(figure 18). This means that somespaces either disappear or integrate with others in post-colonial, the position of maximum accumulation of spaces ${ }^{6}$, illustrate that the post-colonials got deeper and have become more segregated but in a homogenous way. The colonials are slightly higher (more integrated) than of the postcolonials regarding the minimum and maximum integration, and have static layout, less adaptable to high the compartmentalized layout, against hierarchal and flexible post-colonial houses

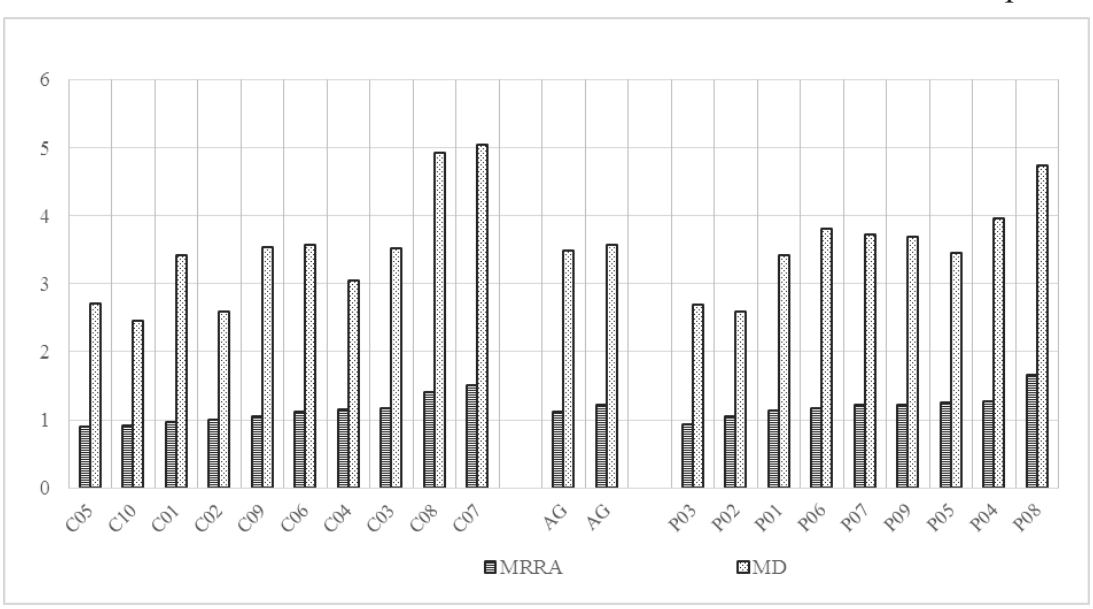

Figure 16. Mean depth and MRRA relationship

5. Non-circulation and exterior spaces (appendix B)

6. The maximum number of nodes in all levels 


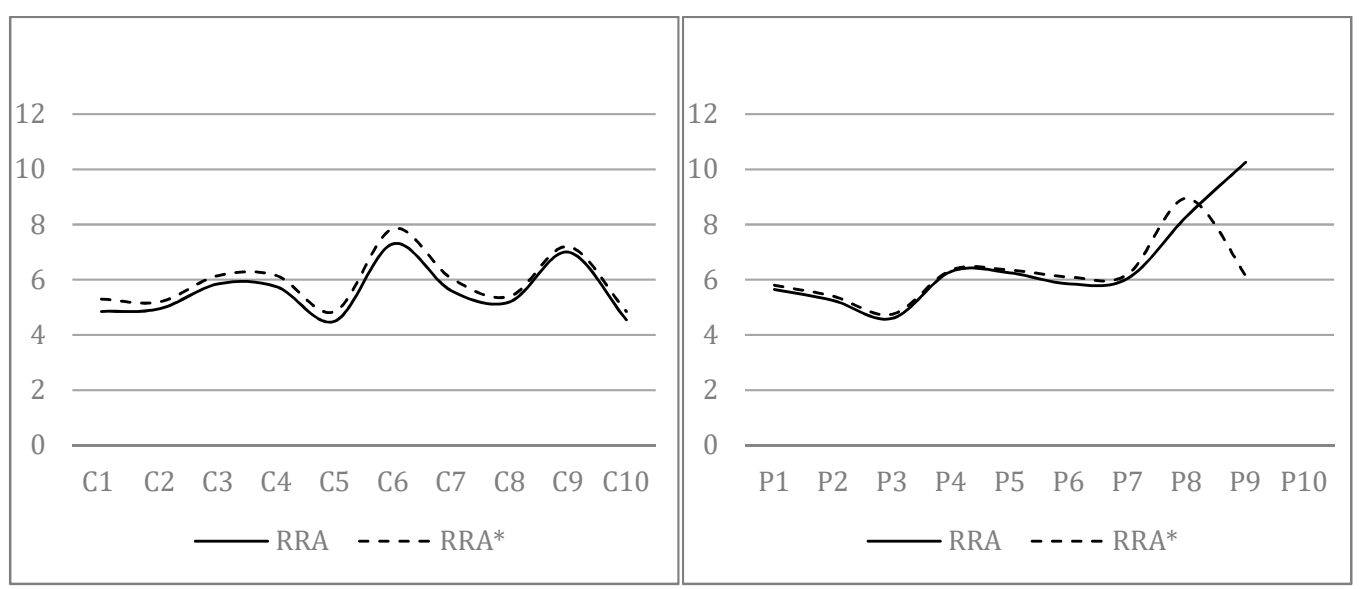

Figure 17. MRRA Integration with and without exterior

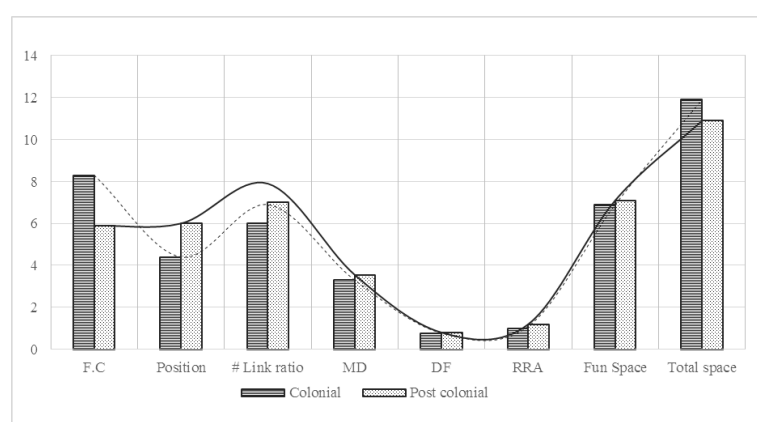

Figure 18. General comparison of syntactical parameters

3.2.2 The categorization (Appendix C) was performed on the dedicated categorical basis (the rank of clusters spaces according to the RRA computed as the mean integration).

Figure 19 shows R1 (high integration of circulation) as the most dominant rank for colonial, R2 (with high dependence on exterior) shows a decrease in its number on the post-colonial. The absence of R1 that links the circulation with exterior is compensated by R3 in post-colonial with more dependence on living spaces. This may

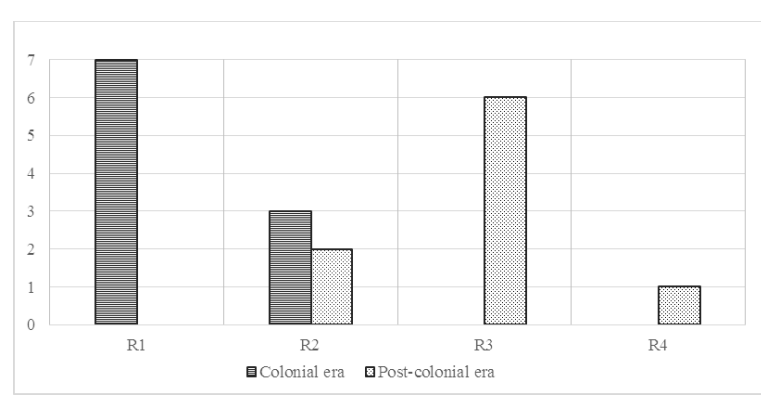

Figure 18. General comparison of syntactical parameters be due to turning to more interior spaces. The remaining $\mathrm{R} 2$ has inverse property value. The new rank R4 with its exclusiveness ${ }^{7}$ for the post-colonial shows living spaces as the most integrated spaces, which give indication for increase in privacy.

\subsection{Maximum and minimum integrated Spaces}

If the maximum and minimum RRA values (table 4) are matched with their corresponding labels, the veranda is the most integrating space ( $50 \%$ of the cases). The other integrating spaces are entrance hall (where found), and foyer (30\% for each), against stair and garden (20\%). The same picture has been reserved but with some changes, entrance hall, and foyer (30\% for each), veranda has been replaced by yard and decreases to $20 \%$, with introduction of sitting room and passages as the most integrated spaces for the post-colonial, this justifies the movement into interior in post-colonials.

In general the most integrated of post-colonial is (regulator + interior) space and for colonial is veranda (exterior space), the Ext:Int ratio increase from 0.27 in colonial to 0.30 in postcolonial supported this turn. This situation has been maintained when the exterior is excluded; all colonial except $(\mathrm{C} 07)$ remain unchanged, while integration values of the post-colonial has increased. The most integrated spaces move 1-2 level deeper in the system. Most segregated service spaces remain as they are, but decrease 1-3 levels.

The least integrated space, $60 \%$ is bathroom for of both periods; the other $40 \%$ is either living or exterior (terrace) for colonial, and

\footnotetext{
7. Same result to Nanta 2009
} 
Table 4. Percentage of the dead end spaces

\begin{tabular}{|c|c|c|c|c|c|c|c|c|c|c|c|}
\hline \multirow{4}{*}{ 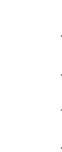 } & Year & \multicolumn{3}{|c|}{ 1-Most LV Spaces } & \multicolumn{3}{|c|}{ 2-Three Most Integrated } & \multicolumn{4}{|c|}{ 3-Guest Domain } \\
\hline & $\mathrm{C} 01$ & $\mathrm{RM}$ & BR & SA & FR & ST In & VR & SA & SI & & \\
\hline & $\mathrm{C} 02$ & RM & SA & BR & VR/GR & RM & SA & SA & - & & \\
\hline & $\mathrm{C} 03$ & LV & SA & SI & VR & GR/ST & LV & LV & SI & SA & \\
\hline \multirow{7}{*}{$\begin{array}{l}\Omega \\
\text { O. } \\
\text { ․․ㄹ. } \\
\text {. }\end{array}$} & $\mathrm{C} 04$ & LV & SA & SI & B-VR & GR & VR & LV & SI & SA & \\
\hline & $\mathrm{C} 05$ & LV & SA & SI & Gr & $\mathrm{RM}$ & B-VR & LV & SI & SA & \\
\hline & C06 & SA & LV & RMs & MS & SA & YR & SA & LV & SI & \\
\hline & $\mathrm{C} 07$ & EH & $\mathrm{DN}$ & SA & Eh & ST In & PG & $\mathrm{EH}$ & DN & SA & FH \\
\hline & $\mathrm{C} 08$ & $\mathrm{DN}$ & FH & RMs & ST & PG & PG & $\mathrm{DN}$ & LV & SA & SI \\
\hline & C09 & SI & SA & $\mathrm{DN}$ & PG & YR & ST & LB & SA & DN & SI \\
\hline & $\mathrm{C} 10$ & $\mathrm{RM}$ & $\mathrm{BR}$ & SA & VR & GR & LB & & RM & SA & \\
\hline \multirow{9}{*}{ 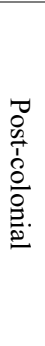 } & P01 & SI & LV & & SI & ST & VR & SI & LV & SA & \\
\hline & $\mathrm{P} 02$ & $\mathrm{EH}$ & $\mathrm{DN}$ & & EH & GR/VR & $\mathrm{DN} / \mathrm{St}$ & EH & DN & & \\
\hline & $\mathrm{P} 03$ & SA & $\mathrm{RM}$ & & $\mathrm{PG} / \mathrm{EH}$ & GR/VR & $\mathrm{SA}+\mathrm{RM}$ & SA & & & \\
\hline & P04 & $\mathrm{EH}$ & $\mathrm{FH}$ & SA & ST & EH & $\mathrm{FH}$ & $\mathrm{EH}$ & SA & SI & \\
\hline & P05 & $\mathrm{EH}$ & $\mathrm{DN}$ & & Eh ST & PG & VR & $\mathrm{EH}$ & DN & & \\
\hline & P06 & EH & SA & & MS & EH SI & GR & $\mathrm{EH}$ & SI & SA & $\mathrm{FH}$ \\
\hline & P07 & $\mathrm{DN}$ & SA & & FR ST & MS & $\mathrm{DN}$ & $\mathrm{DN}$ & $\mathrm{FH}$ & SA & \\
\hline & P08 & SA & RM & LV & YD & TR & $\mathrm{PG}$ & $\mathrm{SA}+\mathrm{DN}$ & SI & & \\
\hline & P09 & FH & $\mathrm{St}$ & $\mathrm{RM}$ & FR ST & FH & VR & FH & SI & LV & SA \\
\hline
\end{tabular}

In: Interior stair

exterior (terrace) or services (store) for post-colonial.

Only $45 \%$ of most integrated spaces in postcolonial are shallow (lie after the MD line (figure 12) and the most segregated stay in deep levels, but only case (P04) merges the preferable space with the most integrated, only $20 \%$ of those integrated spaces are in high connectivity level. The majority of the distributions of rooms found in the last chain, the rest are in between family hall and saloon, which justifies the increased level of function speciality.

1 - $80 \%$ of most integrated spaces in colonials are shallow (lie before or with the MD line) and most preferable ${ }^{8}$ space, but only $60 \%$ of those integrated spaces have high connectivity value. The distribution of rooms within family hall, and saloon occupy different locations between: last- in between- and in last and before. This may be explained that rooms have not had special functions and turn to change their use and position.

2- In general, the three most integrated spaces are: $(33.3 \%$ to $44.4 \%)$ for circulation, $(50 \%$ and $44.4 \%)$ for exterior, $(20 \%$ to $26 \%$ ) for living space. This increase in the circulation and living spaces, and the decrease in exterior value cause the shift to internal zones of post-colonial.

3- Both saloon (guests' domain) and living rooms constitute $33 \%$ of the first level of integration spaces of figure 20 , compared to the entrance hall in post-colonial. The second level, which is usually occupied by sitting in both periods, increased in post-colonial. The family hall replaced the sitting of the colonial in the fourth level in the post-colonials.
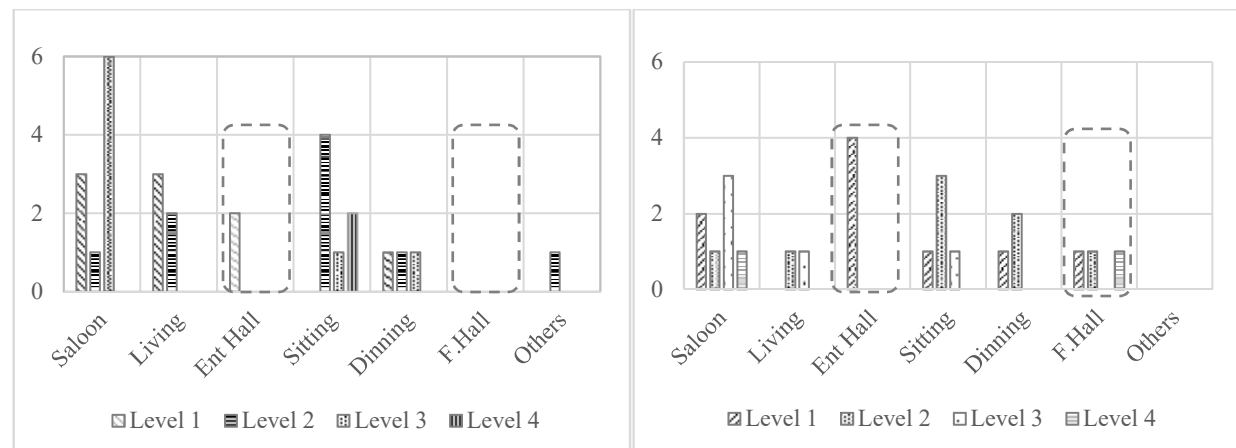

Figure 19. Distribution of living spaces correlated to level occurrences

8. Inhabitants admitted this in the interviews 


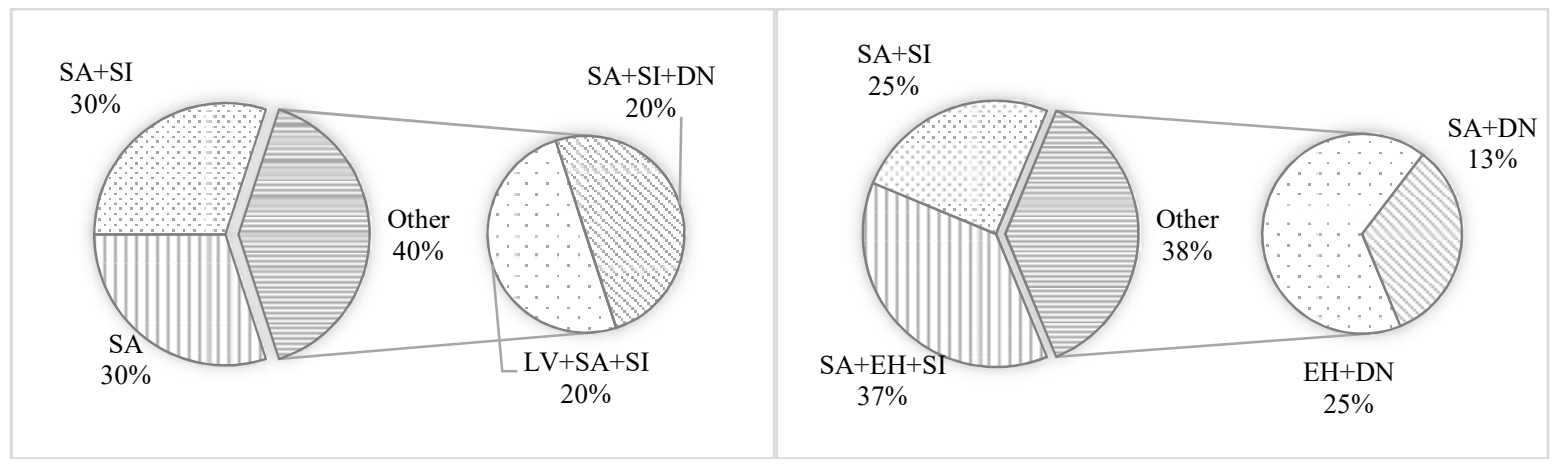

Figure 20. The percentage of the saloon clusters patterns

Figure 19 shows a reduction in the saloon position (go deeper) in post-colonial, and that the family hall, a merit for post-colonial, occupies different levels. Saloon vs. family hall is indicative of the transition from social relations to family relations.

Figure 20 shows the different patterns of saloon. In colonial, [Saloon] and [Saloon + Sitting] were the most dominant patterns $(30 \%$ for each), and the [three patterns] have the least percentage. Later the change in this faculty was regarding its arrangement (from chain in colonial to 'distributness' in post-colonial). Post-colonials, the [three component pattern] has the largest group with $37 \%$, followed by $25 \%$ for [one cluster].

The increase of clusters number may be due to the lifestyle of that time, more leisure time in the evenings is devoted to socializing and chatting. Consequently, this may contribute to the increasing specificity of spatial categories within the interior spaces of the late colonial. The pattern of [Saloon+ Dining] that has continued to the post-colonial has developed to [Entrance hall+ Dinning]. This means that the Entrance hall acts as a saloon and distributed circulation space at the same time.
3.3.1 The percentage of saloon (visitor's domain), family hall (inhabitant's domain), kitchen (servant domain) of figure 21 was compared with correlation to the least and most integrated space in each case, to examine progress, regress or remaining of these spaces.

For the saloon: In colonials (even it does not label), It fluctuates from "most segregated space" to $85 \%$ near the most integrated space; compared to $37-96 \%$ in post-colonial. This may be due to the inhabitants' desire not to involve the visitors deeper in the house. On average of $65 \%$ and $76 \%$, respectively, means an increased level of integration of this space.

For the family hall: In colonials: It fluctuates from $22 \%$ to $95 \%$, and of $67-95 \%$, for postcolonial. In most cases except (P01, P06) are above the $80 \%$. This space in all cases has the property of high connectivity. They end up with an average of $66 \%$ and $85 \%$, which means an increased level of integration again for the post-colonial.

For the kitchen: Half of the colonial show that the kitchen as the most segregated space, in other cases near or on the way to the end pole of

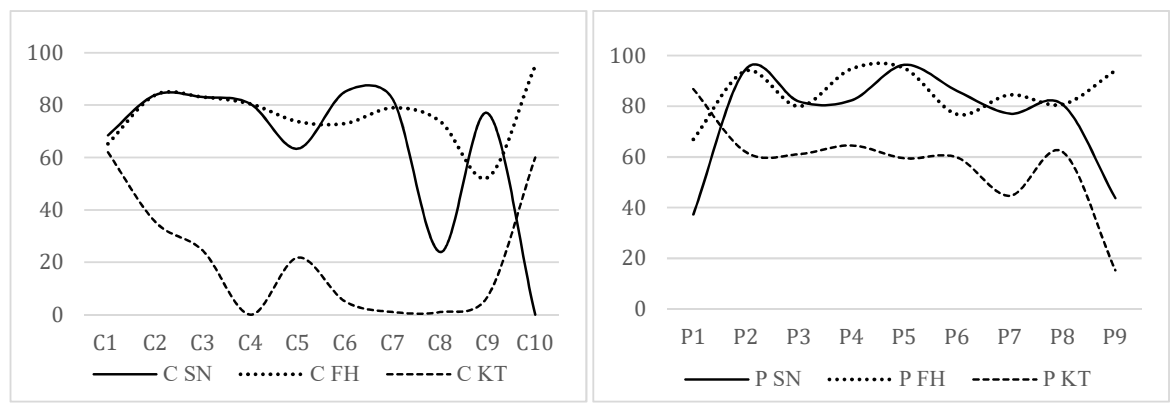

Figure 21. Spaces Occurrence between colonial and post-colonial 


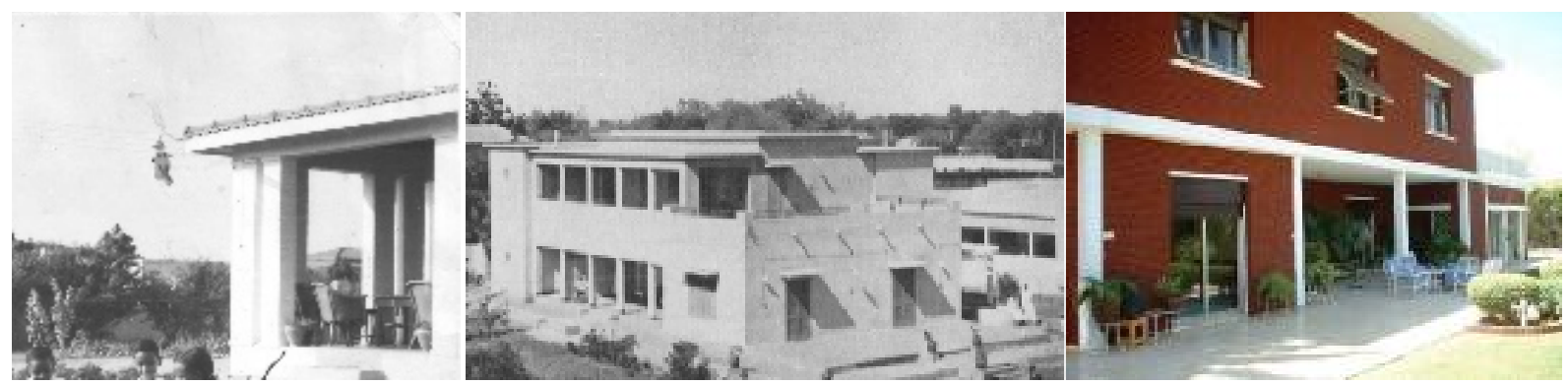

Figure 22. Occurrence of verandah in colonial houses C10, C08 (left) to post-colonial P05 (right). (Source: Owners' album, Hamadan (1969), Author)

segregation. The situation of post-colonial is pretty different; two cases (P07, P09) are near but not the most segregated space. Other six tie around 60\% and only case (P04) shows a relatively high level of integration. They average $19 \%$ and $57 \%$, respectively, shows increased levels of integration for the post-colonial merely in terms of proximity. The Kitchen is never integrated in all cases before dinning, but they integrated more than the saloon and living spaces.

3.3.2 The arrangements of veranda in figure 22 act differently, and identify the significant changes. It lies in front of most spaces in colonials, then it disappears in many post-colonials before it retains, with similar function of balcony or terrace which is normally located in front of bedrooms. The change associated with this space differs quite markedly. Approximately half of the selected cases have undergone changes in its internal spaces, but only cases in the post-colonial are subjected to change in verandah to kitchen or saloon extension, against colonial, which change the verandah to saloon or bedroom, or living room.

Figure 23, shows the dominant feature of $80 \%$ of colonials for type two (front and back), it decreased to $29 \%$ in post-colonial. The absence of type 3 (exclusively in colonials), was compensated by excessive occurrence of type 1 with $71 \%$ in the post-colonial. The front veranda acts as movement regulator while the back veranda, most of the times, is more important than the front.

The attachment of verandah of table 5 to adjacent space was similar in both periods, but the mechanism of their transformation concentrates on the addition and adjustment of space:

- It turns to living space expanded to the outside, when it faces garden,

- It acts as a service space, when faces the kitchen,

- It is likely to face both a service space and a living space (For cases with the verandah at corners).
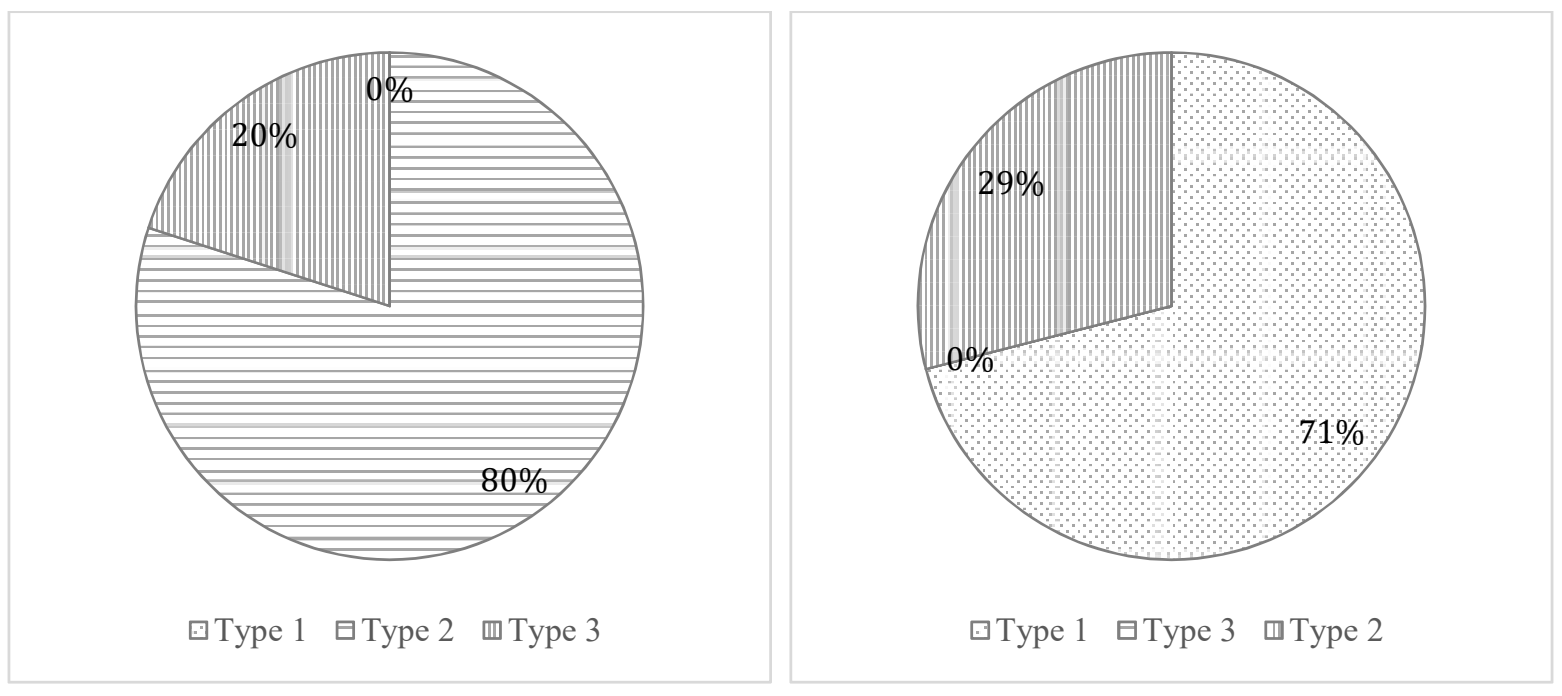

Figure 23. Spaces Occurrence between colonial and post-colonial 
Table 5. Verandah types found in all Cases*

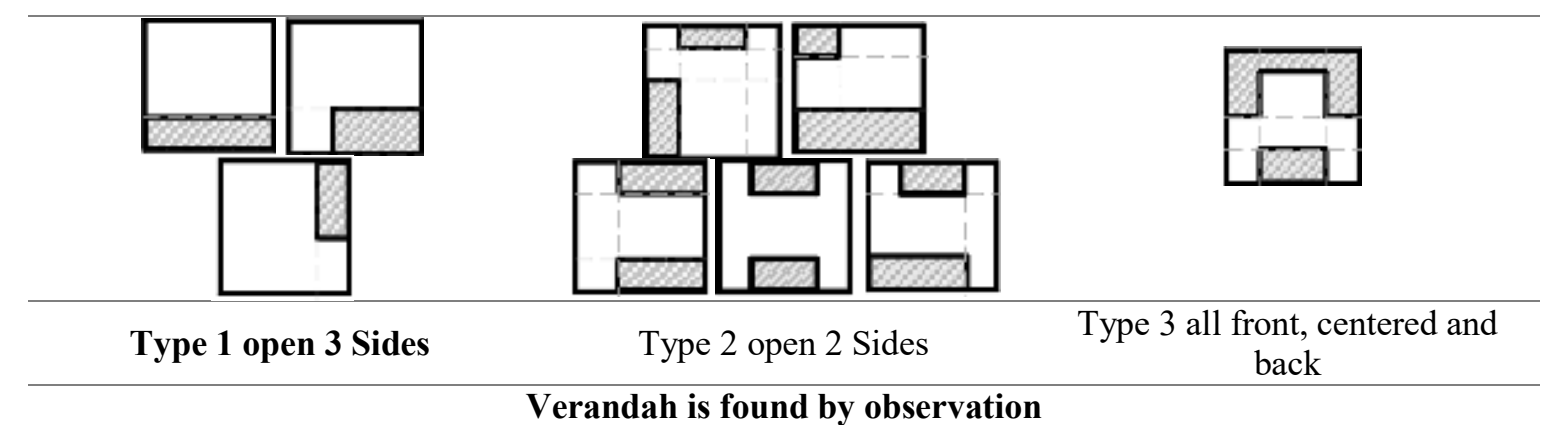

* Adopted from (Watanabe,2004)

\section{CONCLUSION 9}

The study examined the transition of spatial organization from pre to post-colonial to define how spatial layout is shaped by the way of life. Despite the variations of arrangement among the cases, space syntax shows that the continuity and the change of built spaces may provide a wide focal picture for the transitional cases.

It reveals that some houses have changed their patterns, but others, due to competition between the two periods, are not indicative of the transition; they fluctuate in a very short of time, ending with accumulative layers of transitions. These layers, which have pointed to the direction of the transition measurement, have led to various differences ${ }^{10}$ in the functions' setting of spaces.

\subsection{Depth and Integration}

The morphology of colonial houses, which seclude clusters of (living + baths + kitchen), tend to be more integrated; while those of post-colonials incorporate their clusters into a single unit and have less integration value. One of the clear differences lies in the relation between internal unit and exterior. The focus of integration has shifted from the exterior to the interior circulation spaces and from shallow spaces, characterized with the highest integration and control values, along with the lowest depth, to the opposite. The function of circulation, therefore, is transposed from the garden to the central space (entrance halls), and then to family halls.

9. Results have been compared with studies of Nanta (2009), Lara (2008), Neeta (2014), Handson (1998) and Hillier and Handson (1984), which match them in sometimes and showed absolutely different picture in others.

10. The use of Saloon, for example, has been turned to reception.
This turn, in the relation-with-exterior, leads to interior-oriented models which have been sustained by: low exterior-to-interior ratio, dependence on garden-and-verandah cluster instead of the yard-andliving cluster, and the rank of integration. Also, this introversion is further emphasized by the increase in integration value when the exterior is ignored. This, interior-oriented pattern leads to functionally more differentiated spaces, spatially smaller, internally more flexible, and socially more hierarchical.

\subsection{Spaces}

The total number of interior spaces has decreased. The combination of segregation and integration may give rise to assignment of only ${ }^{11}$ single function to each space. Change the nature of multifunctional character of the space, for instance toilet and baths are unified together. Some other spaces could be incorporated into one space for occasional use. Other changes in the spaces, in term of removal (that no longer existing) or growth (the increase in the number of spatial units), led to some variation in the allocation of spaces. For instance, the spatial position of the saloon changed from highly shallow and segregated, to integrated to other space, also the late colonials are condensed around considerable number of bedrooms, and incremental guest's spaces [saloon-sitting- living- and dinning], while postcolonial have new spatial unit like [self-contained room], and new guest quarter [saloon +bath +room]

The highlight of space changes can be summarized as follows:

- The veranda and terrace, in some cases, rarely exist; because they were consolidated into one large levelled platform or living space.

11. Sometimes put moveable bed for seating. Therefore, the area can be provisional used as bedroom or as sitting. 
- The kitchen never appears in the front. This may be due to the inhabitants' preference to isolate themselves from servants.

- The decreased number of bathrooms, despite the increase level of adjacency and technology has resulted from pragmatic reasons or from the little gendercide in using the bath. Both spaces actually have begun to sequence into a chain, with closer access to living spaces (bedrooms and sitting rooms).

- The Interior-oriented change, led to the emergence of Family hall (which was not labeled in colonials), is mediating rather than controlling other spaces, as non-integrated space, unlike the visitor's spaces in colonials. This transition reflects the change in the level of interactions among family and society. Social spaces, which are now assigned to inhabitants, used to occupy the most integrated ${ }^{12}$ spaces, while guests' spaces tend to occur in shallow locations.

- The Entrance hall, the core of Transition-centered model, shows a remarkable transformation. It has shallow depth, gives the opportunity to divide into family and a space for visitors. The emergence of this space, replaced the old function-centered model, which was managed by a saloon. Evidently, this characteristic indicates that premise size did not influence the different integrated levels of its incorporation ${ }^{13}$ with another space; either it appears with a saloon, or with and without a verandah in front.

- While Saloon has disappeared completely in some cases, other cases show two spaces labeled as saloon. The inhabitants may have preferred to accommodate different guest's domains (female, male). When saloon engages with the stair, it turns to be an Entrance hall as both pivotal, living space and circulation distributor. In addition, the emergence of new guest quarter, which includes a mediating saloon, sitting, attached bedroom and bathroom, because of relatives ${ }^{14}$ whom are accommodated and served without disturbing the privacy of inhabitants.

- The cases where the saloon is more integrat-

12. All this spaces confirms with mentioned interviews

13. This result is unlike Kramel (1996) assumptions of the emergence of inner hall is due to integration of verandah to the near space. 14. Relatives who came from outside Khartoum and subject to stay for period of time. ed than the sitting ${ }^{15}$ rooms (early colonial, and early post-colonial), suggest a relatively shallow house, in which guests are quickly admitted to the more integrated areas of the house, and the sitting was planned in a way to exclude the interactions of family members ${ }^{16}$.

- The cases where the living room and the entrance hall are more integrated than the saloon, indicate the purpose of entertaining the guest through different spaces.

- Shallow bedrooms wherever found, are more integrated, suggests that some guests are received here too.

The organization and use of spaces have evolved in relation to the changed cultural and the life styles between different groups. These groups occupied different period in Khartoum produced different spatial qualities. However, it is still difficult to assess the full influence of this transition; considering only space syntax, another analysis is required to complement the picture. Analysis such semiological study, technology advances and economic changes are going to be important facets of transition.

\section{REFERENCES}

Ashley, Jackson, Buildings of Empire, London, Oxford, (2013).

Bandyopadhyay, A., Merchant, A., "Space Syntax Analysis of Colonial Houses in India”, Environment and Planning B, Planning and Design, 33, (6), (2006): 923-942.

"Space Syntax - A Tool for Understanding Spatial Organization and its Change Over Time”. N.p, 2015, Web. 4 April, (2019).

Bafna, Sonit, "Space Syntax: a Brief Introduction to Its Logic and Analytical Techniques", Environment \& Behavior. 35, (1), (2003): 17-29.

Bani, Maha, "Critical Regionalism: Studies on Contemporary Residential Architecture of Khartoum - Sudan", Unpublished MSc thesis, Faculty of Architecture, University of Khartoum, (2014).

Bashier, Fathi, Modern Architecture in Khar-

15. Although the sitting room (English culture) and saloon (French culture) are referred to same space, Sudanese people tend to use both of them as different spaces

16. Similar results to Bandyopadhyay \& Merchant (2006). 
toum 1950-1990, Working Paper, School of Architecture and Environmental Planning, Sharq El-Neel College, Sudan, (2007).

Collins, Carole, Colonialism and Class Struggle in Sudan, Cambridge, MA, Middle East Research \& Information Project, (1976).

Daly, M., Hogan, J., Images of Empire: Photographic Sources for the British in the Sudan, The Netherlands, Brill, (2005).

Dursun, P., Saglamer, G., "Spatial Analysis of Different Home Environments in the City of Trabzon, Turkey", Proceedings, 4, London (2003).

Ekhaese, Eghosa, "Benin Domestic Architecture "a tabula rasa" for Transition: From Pre-Independence to Contemporary Architecture", International Journal of Social Sciences and Entrepreneurship, 1, (9), (2014): 264-287.

Elhassan, I., "Khartoum: A Portrait of an African Colonial City", Dirasat Ifriqiyya, N.p, 2016, Web, 8 May, 2019.

Erman, Onur, "From Traditional to Modern: Changes in the Spatial Structure of Single Family Houses in Turkey", International Journal of Academic Research, 6, (5), (2014): 64-74.

Folkers, Antoni, Modern Architecture in Africa, Amsterdam, Uitgeverij Boom, (2010).

Hanson, Julienne, Decoding Homes and Houses, Cambridge, Cambridge University Press, (1998).

Hillier, B., Hanson, J., The Social Logic of Space, Cambridge, Cambridge University Press, (1984).

Hamadan, Gamal, "The Growth and Functional Structure of Khartoum", Geographical Review, 50, (1), (1960) 21-40.

Ibrahim, M., et al, "Evolution and Changes in the Morphologies of Sudanese Cities" Urban Geography, 35, (5), (2014): 735-756.

Kramel, H.E., Khartoum: A Profile of Urban Housing, Zurich, Habitat Group, (1995).

King, Anthony. D., Postcolonial Cities, N.p., 2009, Web, 7 May, 2019.
Lara, Fernando. L., The Rise of Popular Modernist Architecture in Brazil, Gainesville, University Press of Florida, (2008).

Lambe, N., Alpana D., "Analyzing Social Relevance of Spatial Organization: ACase Study of Traditional Pol Houses, Ahmedabad, India", Asian Social Science, 12, (9), (2016): 35-53.

Metcalf, Thomas. R., "Architecture and the Representation of Empire: India, 18601910", Representations, 6, (1984): 37-65.

Nanta, Piyarat, "Social Change and the Thai House: A Study of Transformation in the Traditional Dwelling of Central Thailand", PhD thesis, University of Michigan, (2009).

Nguluma, Huba. M., Housing Themselves: Transformations, Modernization and Spatial Qualities in Informal Settlements in Dar Es Salaam, Tanzania, Stockholm, Kungl Tekniska Högskolan, (2003).

Osman, Omer, et al, Architecture in Sudan 1900-2014; an Endeavour against the Odds, Unpublished publication, (2014).

Sharkey, Heather. J., Living with Colonialism: Nationalism and Culture in the Anglo-Egyptian Sudan, Berkeley, University of California Press, (2003).

Schulz, Noberg, Genius Loci: Towards a Phenomenology of Architecture, New York, Rizzoli, (1980).

Thungsakul, Napadon, A Syntactic Analysis of Spatial Configuration towards the Understanding of Continuity and Change in Vernacular Living Space: A Case Study in the Upper Northeast of Thailand, Ann Arbor, MI, Bell \& Howell Information and Learning Company, (2002).

Vongvilay, X., et al, "The Influence of French Colonial Rule on Lao Architecture with a Focus on Residential Buildings", Journal of Asian Architecture and Building Engineering, 14, (2), (2015): 279-286.

Watanabe, Miki, "Function and Exterior Design of Verandaed Colonial Houses in New South Wales", The Otemon Journal of Australian Studies, 30, (2004): 151-162. 
APPENDIX A- Case Information

Case studies information

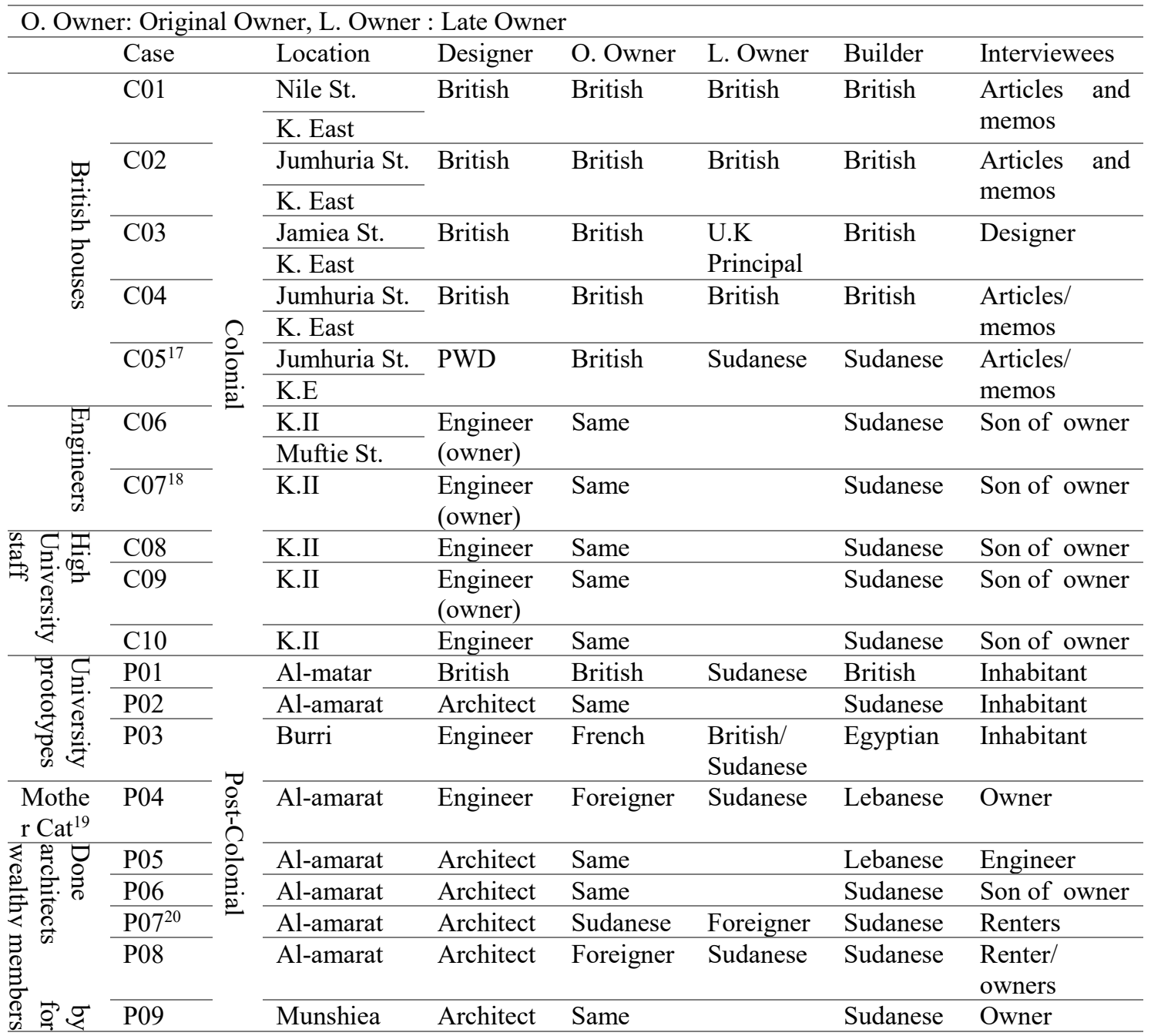

17. And above 6 others by PWD, but one was chosen.

18. Interviewee had bought an existing house that was designed by foreigner engineer.

19. It was a Lebanese company during 1960s for designing and built houses.

20. Conflicting information regarding dates of case 1965 s to be 1969 , and 1966 to be 1963 , and for 1956 to be 1956 , this thesis accepts the first date. 


\section{APPENDIX B- Spatial Analysis 01.}

\section{Spaces analysis}

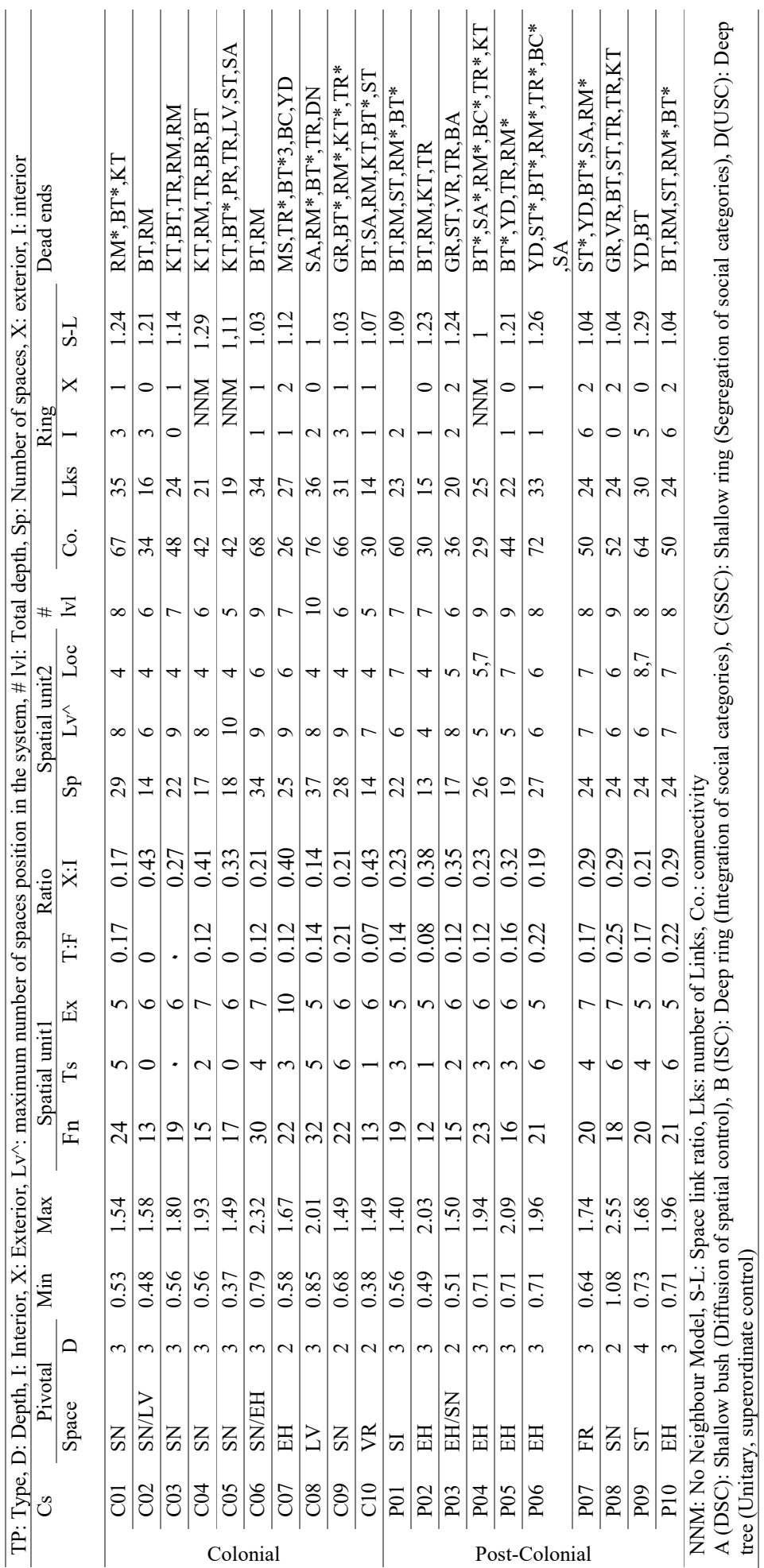


APPENDIX B- Spatial Analysis 02.

Spaces analysis
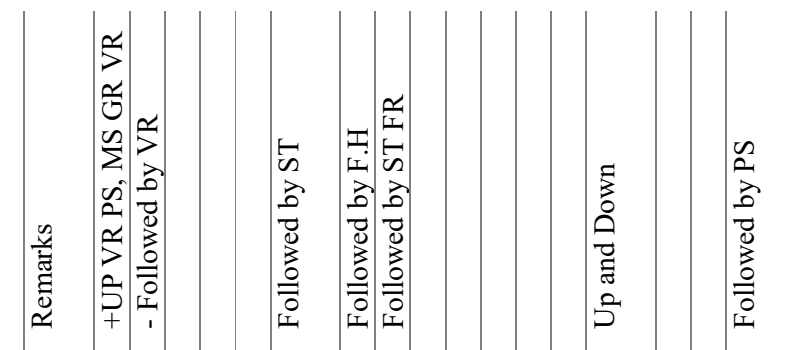

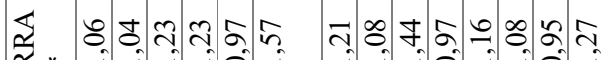

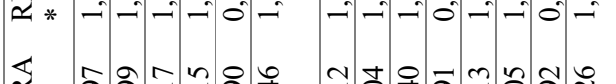

药

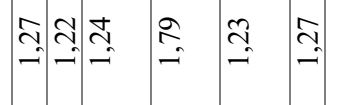

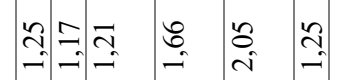

$\hat{\theta}|x| x|x|$

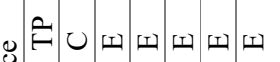

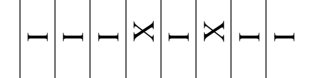

कूँ

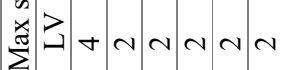

ــ

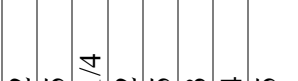

$\stackrel{x}{>}$

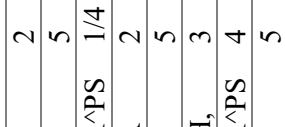

๘

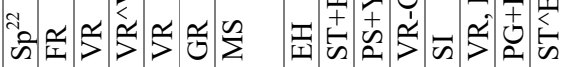

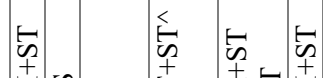

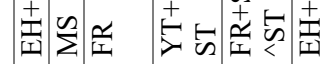

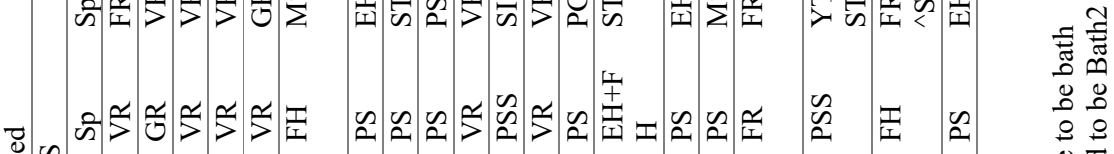

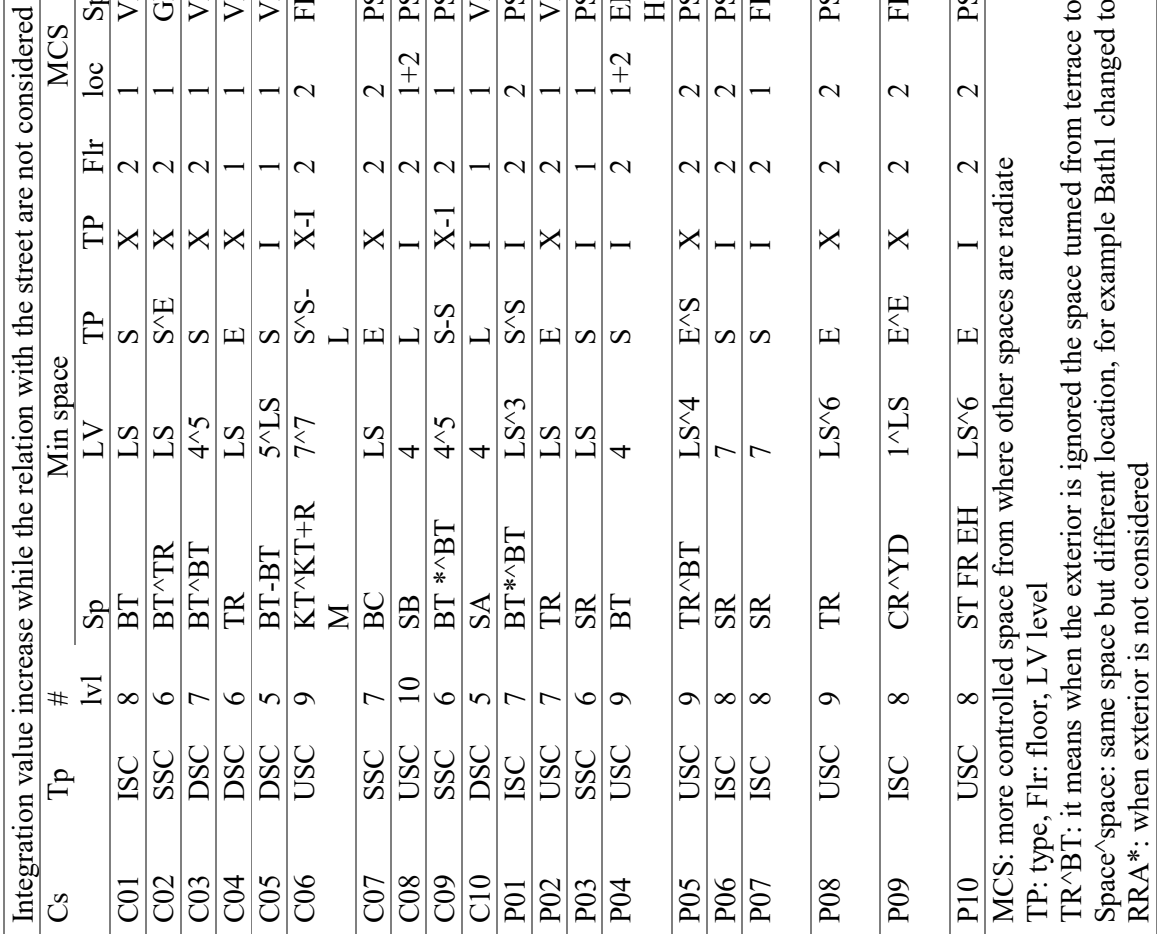

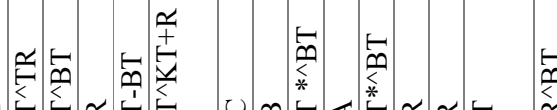

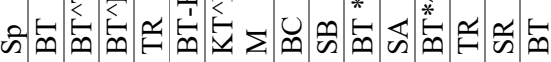

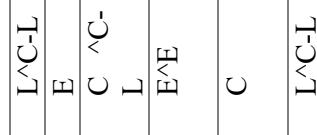

$\frac{4}{4} \frac{m}{4} \operatorname{4} \frac{d}{\mathrm{n}}$ 


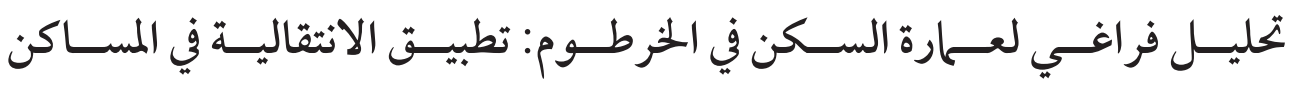

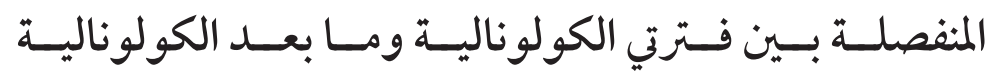

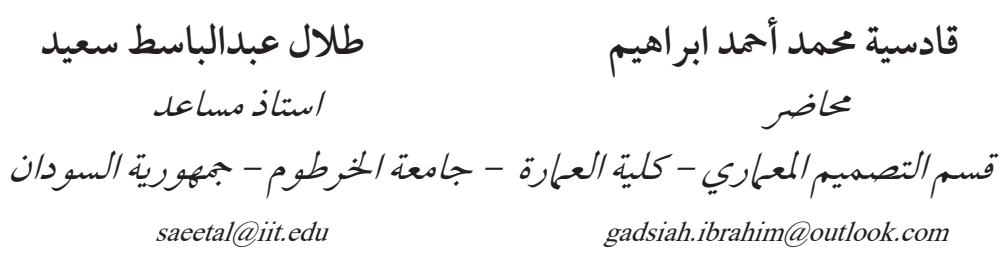

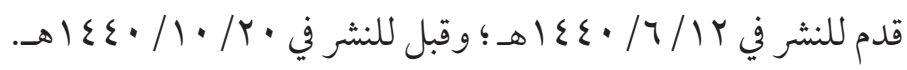

ملخص البحث. عبّرت التغيُّرات المعقّدة لأنماط عمارة السكن في الخُرطوم، عن الاختلاف في القيم الاجتماعية

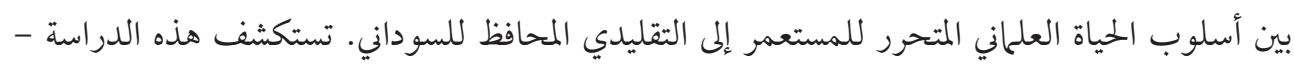

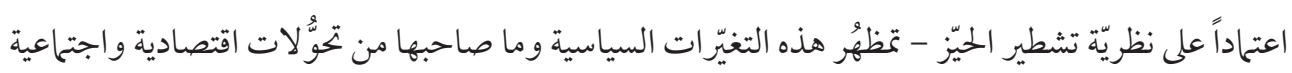

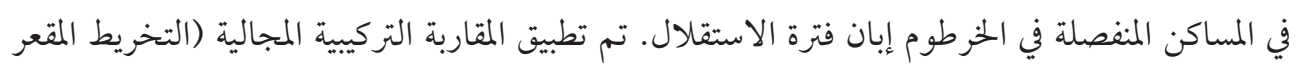

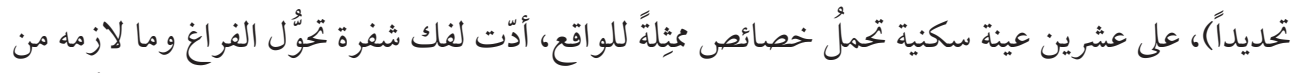

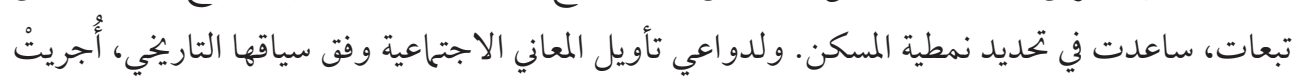

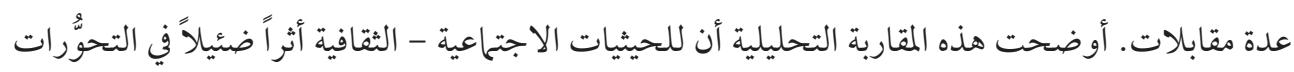

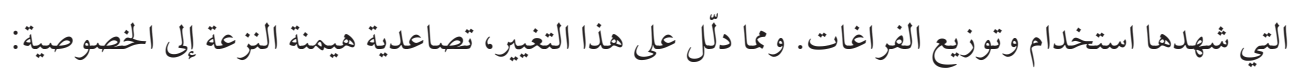

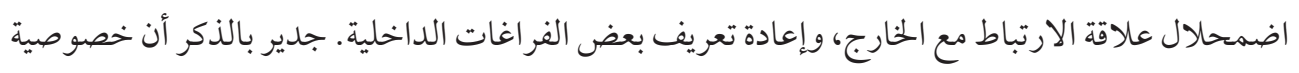
توجه أنماط عينات ما بعد الاستقلال عمّقت من تموضع جوهر الاتصاليّة في خخطط المو صُولية. 